\title{
Diagnosis, treatment and prevention of pediatric obesity: consensus position statement of the Italian Society for Pediatric Endocrinology and Diabetology and the Italian Society of Pediatrics
}

Giuliana Valerio $^{1^{* \dagger}}$ (D), Claudio Maffeis ${ }^{2+}$, Giuseppe Saggese ${ }^{3}$, Maria Amalia Ambruzzi ${ }^{4}$, Antonio Balsamo ${ }^{5}$, Simonetta Bellone ${ }^{6}$, Marcello Bergamini ${ }^{7}$, Sergio Bernasconi ${ }^{8}$, Gianni Bona ${ }^{6}$, Valeria Calcaterra ${ }^{9}$, Teresa Canali ${ }^{10}$, Margherita Caroli ${ }^{11}$, Francesco Chiarelli ${ }^{12}$, Nicola Corciulo $^{13}$, Antonino Crinò ${ }^{14}$, Procolo Di Bonito ${ }^{15}$, Violetta Di Pietrantonio ${ }^{16}$, Mario Di Pietro ${ }^{17}$, Anna Di Sessa ${ }^{18}$, Antonella Diamanti ${ }^{19}$, Mattia Doria ${ }^{20}$, Danilo Fintini ${ }^{21}$, Roberto Franceschi ${ }^{22}$, Adriana Franzese ${ }^{23}$, Marco Giussani ${ }^{24}$, Graziano Grugni ${ }^{25}$, Dario lafusco ${ }^{18}$, Lorenzo lughetti ${ }^{26}$, Adima Lamborghini ${ }^{27}$, Maria Rosaria Licenziati ${ }^{28}$, Raffaele Limauro ${ }^{29}$, Giulio Maltoni ${ }^{5}$, Melania Manco ${ }^{30}$, Leonardo Marchesini Reggiani ${ }^{31}$, Loredana Marcovecchio ${ }^{12}$, Alberto Marsciani ${ }^{32}$, Emanuele Miraglia del Giudice ${ }^{18}$, Anita Morandi ${ }^{33}$, Giuseppe Morino ${ }^{34}$, Beatrice Moro ${ }^{35}$, Valerio Nobili ${ }^{36,37}$, Laura Perrone ${ }^{18}$, Marina Picca ${ }^{24}$, Angelo Pietrobelli ${ }^{38}$, Francesco Privitera ${ }^{39}$, Salvatore Purromuto ${ }^{40}$, Letizia Ragusa ${ }^{41}$, Roberta Ricotti ${ }^{6}$, Francesca Santamaria ${ }^{23}$, Chiara Sartori ${ }^{42}$, Stefano Stilli ${ }^{31}$, Maria Elisabeth Street ${ }^{42}$, Rita Tanas ${ }^{43}$, Giuliana Trifiró ${ }^{44}$, Giuseppina Rosaria Umano ${ }^{18}$, Andrea Vania ${ }^{36}$, Elvira Verduci ${ }^{45}$ and Eugenio Zito ${ }^{46}$

\footnotetext{
Abstract

The Italian Consensus Position Statement on Diagnosis, Treatment and Prevention of Obesity in Children and Adolescents integrates and updates the previous guidelines to deliver an evidence based approach to the disease. The following areas were reviewed: (1) obesity definition and causes of secondary obesity; (2) physical and psychosocial comorbidities; (3) treatment and care settings; (4) prevention.

The main novelties deriving from the Italian experience lie in the definition, screening of the cardiometabolic and hepatic risk factors and the endorsement of a staged approach to treatment. The evidence based efficacy of behavioral intervention versus pharmacological or surgical treatments is reported. Lastly, the prevention by promoting healthful diet, physical activity, sleep pattern, and environment is strongly recommended since the intrauterine phase.
}

Keywords: Consensus, Diagnosis, Pediatric obesity, Prevention, Treatment

\footnotetext{
* Correspondence: giuliana.valerio@uniparthenope.it

${ }^{+}$Giuliana Valerio and Claudio Maffeis contributed equally to this work.

${ }^{1}$ Department of Movement Sciences and Wellbeing, University of Naples

Parthenope, via Medina 40, 80133 Naples, Italy

Full list of author information is available at the end of the article
}

(c) The Author(s). 2018 Open Access This article is distributed under the terms of the Creative Commons Attribution 4.0 International License (http://creativecommons.org/licenses/by/4.0/), which permits unrestricted use, distribution, and reproduction in any medium, provided you give appropriate credit to the original author(s) and the source, provide a link to the Creative Commons license, and indicate if changes were made. The Creative Commons Public Domain Dedication waiver (http://creativecommons.org/publicdomain/zero/1.0/) applies to the data made available in this article, unless otherwise stated. 


\section{Background}

Contrasting pediatric obesity is among the priority goals in the healthcare agenda of the Italian National Healthcare System. Beyond the high prevalence and persistence of pediatric obesity [1], robust evidence demonstrates that physical and psychosocial complications are already present in obese children [2] and worsen in adulthood. Therefore, prevention and treatment of pediatric obesity and complications are key strategic goals, in order to reduce morbidity, mortality, and expected costs for the care of obese adults.

The very fruitful scientific research on pediatric obesity of the last decade justified to update the guidelines, in order to provide the best evidence-based reccomendations. Therefore, the Italian Society for Pediatric Endocrinology and Diabetology and the Italian Society of Pediatrics, with other Pediatric Societies joined in the common objective of contrasting pediatric obesity, made this Consensus on "Diagnosis, therapy and prevention of obesity in children and adolescents", updating the document published in 2006 [3].

\section{Methods}

Four main topics were defined: 1) diagnostic criteria, secondary obesity; 2) comorbidities; 3) treatment and care settings; 4) prevention. Coordinators were identified for each topic and specific questions listed. Twenty experts' groups were set up, embracing all the skills needed for document processing. Each group systematically revised the literature on the assigned themes limited to the time frame 1 January 2006 to 31 May 2016 and patients' age range $0-18$ years. The article search was done through PubMed using MeSH terms or descriptors. Scientific articles, systematic reviews, meta-analysis, consensus, recommendations, international and national guidelines published on pediatric obesity even prior to 2005 were considered and deemed useful to the Consensus. The level of evidence (LOE) and the grade of raccomendation were established in accordance with the National Manual of Guidelines [4] (Additional file 1). Each working group prepared a preliminary draft reporting LOE for each specific recommendation, followed by a brief description of the scientific evidence in support, epidemiological data, and any notes deemed as useful. A Consensus Conference was held in Verona, on June 9th, 2016 in the presence of the document extensors and delegates of the Scientific Societies to discuss and approve the preliminary draft. The final document was sent on October 10th, 2016 to all the extensors and members of the Pediatric Obesity Study Group of the Italian Society for Pediatric Endocrinology and Diabetology and approved on 28th February 2017 in its definitive form. Literature search was updated before preparing the final draft; no additional relevant publication was identified which might have required a change in the statements.

\section{Diagnosis \\ Diagnostic criteria for defining overweight, obesity and severe obesity \\ The definition of overweight and obesity is based on the use of percentiles of the weight-to-length ratio or body mass index, depending on sex and age. LOE V-A}

In children up to 24 months, the diagnosis of overweight and obesity is based on the weight-to-length ratio, using the World Health Organization (WHO) 2006 reference curves [5]. After the age of 2 years it is based on the Body Mass Index (BMI), using the WHO 2006 reference system [5] up to 5 years and the WHO 2007 reference system [6] thereafter (Table 1). The recommendation of using the WHO standard is based on the need to propose a reference system which, although is not an ideal model to assess adiposity in single children or groups, it has a greater sensitivity in identifying children and adolescents with overweight and obesity, in a period of particular seriousness of the pediatric obesity epidemic in Italy. On the contrary, the Italian BMI thresholds [7] underestimate the prevalence of obesity compared to WHO, probably because they were based on measurements taken during the epidemic increase of obesity [8].

\section{The cut-off to define severe obesity is represented by the $B M I>99$ th percentile. $L O E$ VI-B}

It has been demonstrated that the 99th percentile of BMI identifies subjects with higher prevalence of cardiometabolic risk factors and persistence of severe obesity in adulthood with respect to the lower percentiles [9]. The WHO system provides the values of the 99th percentile of BMI which approximate + 3 SDS from 2 years upwards. However, as for overweight and obesity classification, the WHO terminology for severe obesity differs between younger ( $0-5$ years) and older children/adolescents (5-18 years): the 99th percentile identifies "obesity" in the former group, and "severe obesity" in the latter. This cautious approach is motivated by the fact that the growth process differs between younger and older children; moreover few data are available on the functional significance of the cut-offs for the upper end of the BMI-for-age distribution in pre-school age [10, 11]. A scientific statement from the American Hearth Association proposed the $120 \%$ above the age and sex 95th percentile of BMI or an absolute BMI $\geq 35 \mathrm{~kg} / \mathrm{m}^{2}$ (equivalent to class 2 obesity in adults) as an alternative to the 99th percentile [12]. The impact of this system using the WHO thresholds has yet to be assessed in clinical practice. 
Table 1 Diagnostic criteria to classify overweight and obesity

\begin{tabular}{llll}
\hline Age & 0-2 years & $2-5$ years & 5-18 years \\
Index & Weight-to-lenght ratio & BMI & BMI \\
Reference & WHO 2006 & WHO 2006 2007 \\
$>85$ th percentile & At risk of overweight & At risk of overweight & Overweight \\
$>97$ th percentile & Overweight & Overweight & Obesity \\
$>99$ th percentile & Obesity & Obesity & Severe obesity \\
\hline
\end{tabular}

athe 85 th, 97 th and 99th percentiles approximate $z$-scores of $+1,+2$ and +3 , respectively

\section{Secondary obesity \\ The clinical suspicion of secondary obesity arises after careful anamnestic, anthropometric and clinical evaluations. LOE III-A}

Obesity may be ascribed to a specific cause (endocrine, hypothalamic, genetic, iatrogenic). Therefore, clinical history, peculiar signs and symptoms must be accurately assessed such as: 1) onset of obesity before 5 years and/ or rapid progression, especially in association with clues suggesting secondary causes (i.e. genetic forms); 2) continuous and/or rapid weight gain associated with reduced height velocity or short stature; 3) delayed cognitive development; 4) dismorphic features; and 5) use of drugs inducing hyperphagia (i.e. corticosteroids, sodium valproate, risperidone, phenothiazines, ciproeptadine) [13].

Early-onset obesity occurring in a child with delayed psychomotor development, cognitive deficiency, short stature, cryptorchidism or hypogonadism, dysmorphisms and characteristic facial features, ocular and/or auditory alterations, is suggestive of a syndromic form [14]. Prader-Willi syndrome is the most common one, whereas Bardet-Biedl, Alström, Cohen, Borjeson-Forssman and Carpenter are more rarely observed [15-20]. Obesity occurs frequently in children with trisomy 21, Klinefelter and Turner syndromes [21-23].

The monogenic forms, albeit uncommon, are nevertheless the most frequent causes of obesity with early onset compared to endocrine and syndromic forms [24] and are due to dysregulated hunger satiety circuits [25]. Certain monogenic forms are characterized by tall or normal stature [14]. Suspicion of syndromic or monogenic forms is confirmed by genetic investigations.

\section{Comorbidities}

Hypertension

Blood pressure measurement is recommended in all children with overweight or obesity from the age of 3 years. LOE I-A

Obesity is the main risk factor for hypertension in children and adolescents [26, 27]. The risk increases with obesity severity [28]. As blood pressure (BP) levels change according to sex, age, ethnicity and obesity, the prevalence of high BP levels and especially hypertension is heterogeneous $(7-30 \%)$ in obese children [29, 30]. White coat hypertension may cause overestimation of the high BP prevalence, but the effect tends to disappear if BP is measured on at least 2-3 occasions [29].

Screening can be anticipated in children $<3$ years if there is a history of neonatal complications, cardiac malformations, genetic diseases, acquired or congenital kidney diseases, neoplasms, drug use, illnesses which induce increased intra-cranial pressure [31] (LOE III-B).

\section{The definition of high BP levels requires a precise methodology and the use of tables expressing by sex and age the percentile of systolic and diastolic blood pressure as a function of the height percentile. LOE III-A}

The method of measuring BP and the definition of high systolic (SBP) and diastolic BP (DBP) values are based on the guidelines of the National High Blood Pressure Education Program Working Group on High Blood Pressure in Children and Adolescents and the European Society for Hypertension (Table 2) [32, 33].

Primary forms of hypertension are mainly associated with obesity and more frequent in children $>6$ years. Secondary forms are predominant in younger children. Nephropathy, nephrovascular pathologies and coarctation of the aorta account for $70-90 \%$ of the causes of secondary hypertension in pediatric age, while hypertension by endocrine causes is rare [34]. Various drugs (steroids, erythropoietin, theophylline, beta-stimulants, cyclosporin, tacrolimus, tricyclic antidepressants, antipsychotics, monoamino oxidase inhibitors, nasal decongestants, oral contraceptives, and androgens) can increase BP. If stage I hypertension is confirmed on 3 different visits, the following diagnostic work-up is recommended: 1) assessment of

Table 2 Definition of the blood pressure values

\begin{tabular}{ll}
\hline Normal BP & $\begin{array}{l}\text { SBP and DBP }<90 \text { th percentile by gender, } \\
\text { age and height }\end{array}$ \\
High normal BP & $\begin{array}{l}\text { SBP and/or DBP } \geq 90 \text { th but }<95 \text { th percentile by } \\
\text { gender, age and height (BP }>120 / 80 \mathrm{mmHg} \text { even } \\
\\
\text { <90th percentile are considered as high normal BP). }\end{array}$ \\
$\begin{array}{l}\text { Hypertension } \\
\text { (Stage I) }\end{array}$ & SBP and/or DBP $\geq 95$ th $<99$ th percentile $+5 \mathrm{mmHg}$ \\
Hypertension & SBP and/or DBP $\geq 99$ th percentile $+5 \mathrm{mmHg}$ \\
(Stage II) & by gender, age and height.
\end{tabular}

BP Blood pressure, SBP Systolic blood pressure, DBP Diastolic blood pressure 
blood urea nitrogen, creatinine, glycemia, electrolytes, lipids, urine examination, microalbuminuria (may be influenced by physical activity) (LOE II-A); 2) measurement of glomerular filtration by formulas for renal function monitorig (LOE III-B); 3) echocardiography to assess organ damage (left ventricular hypertrophy, altered cardiac structure) (LOE III-A) [35]. Left ventricular remodeling or concentric hypertrophy are associated with high BP levels and other comorbidities such as visceral obesity and atherogenic dyslipidemia [36, 37]. Weight loss and reduced sodium intake are recommended. If stage II hypertension or secondary causes are present, the patient must be referred to a specialist for further investigations and treatment $[31,34,35]$.

\section{Prediabetes and type 2 diabetes mellitus}

Fasting blood glucose measurement is recommended in all children and adolescents with overweight and obesity since the age of 6, as the first step for screening prediabetes and type 2 diabetes. LOE $V$ - $A$

The diagnosis of prediabetes, i.e. high fasting blood glucose and impaired glucose tolerance (IGT) or overt type 2 diabetes (T2D) is based on fasting plasma glucose or oral glucose tolerance test (OGTT) [38]. The use of hemoglobin glycosilated A1c (HbA1c) is still controversial in pediatric age [38-42]. The criteria for defining prediabetes and T2D are summarized in Table 3. The screening must be repeated after 3 years, unless rapid weight increase or the development of other cardiometabolic comorbidities occur. Since evidences provided from national studies suggest that prediabetes is already present in about $5 \%$ obese children $<10$ years [43], it is recommended to start the screening by testing fasting glucose in all overweight or obese children after the age

Table 3 Criteria for the diagnosis of prediabetes and diabetes mellitus

Prediabetes Impaired fasting glucose: plasma glucose (after $8 \mathrm{~h}$ of fasting) between $100(5.6 \mathrm{mmo} / \mathrm{l})$ and $125 \mathrm{mg} / \mathrm{dl}(6.9 \mathrm{mmol} / \mathrm{l})$

Impaired glucose tolerance: plasma glucose after $2 \mathrm{~h}$ of the OGTT between 140 and $199 \mathrm{mg} / \mathrm{dl}(7.8 \mathrm{mmol} / \mathrm{l})$

$\mathrm{HbA1c}$ between $5.7-6.4 \%(39-47 \mathrm{mmol} / \mathrm{mol})$

Type 2 diabetes Random glycemia $\geq 200 \mathrm{mg} / \mathrm{dl}(11.1 \mathrm{mmol} / \mathrm{l})$ and

symptoms suggestive of diabetes (glycosuria without ketonuria,

polydipsia, weight loss). Confirmation with a second test is not

necessary. If symptoms are lacking, diagnosis is made whether one of the following criteria is fullfilled:

1. Fasting glycemia $\geq 126 \mathrm{mg} / \mathrm{dl}$ after $8 \mathrm{~h}$ of fasting.

2. Glycemia $\geq 200 \mathrm{mg} / \mathrm{dl}$ after $2 \mathrm{~h}$ of the OGTT.

3. $\mathrm{HbA} 1 \mathrm{c} \geq 6.5 \%$ or $\geq 48 \mathrm{mmol} / \mathrm{l}$ (IFCC reference method using high-

performance liquid chromatography (caution in pediatric age). If one test is positive, the diagnosis must be confirmed by a second test. Whenever the two tests are discordant, the patient should be strictly monitored and the positive test repeated within 3-6 months. If the diagnosis of diabetes is made, the assessment of the autoimmune markers (ICA, GAD, IA2, IAA ○ $\mathrm{ZnT}$ \%) is needed to exclude type 1 diabetes.

Genetic screening for monogenic diabetes is recommended in the rare cases presenting with obesity, diabetes, negative autoimmunity tests and family history for T2D. of 6 years. The OGTT is indicated after the age of 10 years or at onset of puberty in agreement with the criteria of the American Diabetes Association [38] (Table 4). Certain conditions, such as non-alcoholic fatty liver disease (NAFLD), fasting blood glucose $\geq 86 \mathrm{mg} / \mathrm{dl}$, or a combination of triglycerides (TG) $>100 \mathrm{mg} / \mathrm{dl}$ plus fasting blood glucose $>80 \mathrm{mg} / \mathrm{dl}$, or $\mathrm{TG}$ to HDL-cholesterol ratio (TG/HDL-C) $\geq 2.2$, have been associated with increased risk of IGT [44-47] and therefore, an OGTT may be considered in latter cases (LOE VI-B) (Table 4).

\section{Dyslipidemia}

The measurement of cholesterol, HDL-cholesterol and triglycerides is recommended in all children and adolescents with obesity since the age of 6. LOE I-A

The dyslipidemic pattern associated with childhood obesity consists of a combination of elevated TG, decreased HDL-C, and low density lipoprotein cholesterol. The prevalence of dyslipidemia among obese children was $46-50.4 \%[48,49]$. Because the association of obesity/hyperlipidemia (expecially hypertriglyceridemia) is predictive of fatal and non fatal cardiovascular events in adult life [50], the screening of dyslipidemia is recommended, and should be repeated after 3 years, if negative, or more frequently if rapid increase in weight or development of other cardiometabolic comorbidities occurs $[51,52]$.

In the absence of national reference values, the diagnosis of dyslipidemia is based on the criteria proposed by the expert panel on integrated guidelines for cardiovascular health and risk reduction in children and adolescents. LOE III-B

The cut-offs for the definition of abnormal lipid levels as proposed by the Expert Panel [51] are summarized in Table 5. Recent studies have shown that the TG/HDL-C ratio is associated with insulin resistance and early organ

Table 4 Indication for the oral glucose tolerance test in children and adolescents with overweight or obesity

Children with fasting plasma glucose $\geq 100 \mathrm{mg} / \mathrm{dl}$ or $\mathrm{HbA1c}$ $\geq 5.7-6.4 \%$ (39-46 mmol$/ \mathrm{mol})$

Adolescents ( $>10$ years of age) or at onset of puberty with overweight

(BMI > 85th percentile) and at least one of the following risk factors:

- Family history of T2DM in first- or second-degree relatives;

- Race/ethnicity (African American, Latino, Native American, Asian American, or Pacific Islander);

- Signs or conditions associated with insulin resistance (hypertension, dyslipidaemia, polycystic ovary syndrome, acanthosis nigricans, or small for gestational age at birth)

Maternal history of diabetes or gestational diabetes during the child's gestation

- Non alcholic liver disease

- TG/HDL-Cholesterol $\geq 2.2$

- Fasting plasma glucose $\geq 86 \mathrm{mg} / \mathrm{dl}$

- TG > $100 \mathrm{mg} / \mathrm{dl}$ and fasting plasma glucose $>80 \mathrm{mg} / \mathrm{dl}$ 
Table 5 References values to define dyslipidemia according to the Expert Panel on Integrated Guidelines for Cardiovascular Health and Risk Reduction in Children and Adolescents ${ }^{60}$

\begin{tabular}{llll}
\hline Cathegory & Acceptable & Borderline-high & High \\
\hline Total cholesterol $(\mathrm{mg} / \mathrm{dl})$ & $<170$ & $170-199$ & $\geq 200$ \\
LDL-cholesterol $(\mathrm{mg} / \mathrm{dl})$ & $<110$ & $110-129$ & $\geq 130$ \\
Non HDL-cholesterol $(\mathrm{mg} / \mathrm{dl})$ & $<120$ & $120-144$ & $\geq 145$ \\
Triglycerides $(\mathrm{mg} / \mathrm{dl})$ & & & \\
0-9 years & $<75$ & $75-99$ & $\geq 100$ \\
10-19 years & $<90$ & $90-129$ & $\geq 130$ \\
& Acceptable & Borderline-low & Low \\
HDL-cholesterol $(\mathrm{mg} / \mathrm{dl})$ & $>45$ & $40-45$ & $<40$ \\
\hline
\end{tabular}

Lipids are determined after at least $12 \mathrm{~h}$ of fasting

$L D L$ Cholesterol is calculated by the Friedewald's formula as total Cholesterol minus $H D L$ cholesterol minus (Triglycerides/5) (provided that triglycerides are $<400 \mathrm{mg} / \mathrm{dl}$ )

Non HDL cholesterol is calculated as total Cholesterol minus HDL Cholesterol

damage (heart, liver, and carotid) [53-55]. The $\mathrm{Tg} /$ HDL-C > 2.2 can be considered as a marker of atherogenic dyslipidemia and an altered cardiometabolic risk profile in obese children in Italy $[55,56]$ (LOE V-A). Children with $\mathrm{TG} \geq 500 \mathrm{mg} / \mathrm{dL}$ or LDL-Cholesterol persistently $\geq 160 \mathrm{mg} / \mathrm{dL}$ need lipid specialist consultation [51].

\section{Gastroenterological complications Non-alcoholic fatty liver disease}

The assessment of transaminases and liver ultrasound is suggested in all children and adolescents with obesity starting at age of 6 years. LOE V-B The prevalence of NAFLD in obese children is $38-46 \%$ [57, 58]. Bright liver on ultrasound examination, with or without elevation of alanine aminotransferase $(>26 \mathrm{U} / \mathrm{L}$ in boys and $>22 \mathrm{U} / \mathrm{L}$ in girls) suggests NAFLD [59]. Weight reduction and re-testing after 6 months are initially recommended [60] (LOE III-A). If liver hyperechogenicity and/or elevated alanine aminotransferase persist despite weight loss, other causes of hepatic disease (i.e. viral hepatitis, Wilson's disease, autoimmune hepatitis, alpha 1 anti-tripsin deficiency, etc.) should be investigated. If ALT persistently exceeds twice the normal limit, the patient must be referred to a pediatric hepatologist [61].

Liver biopsy is the gold standard for diagnosis, but its invasiveness and the possible complications limit its use only to selected cases [61] (LOE VI-A).

Assessment of biochemical markers (i.e. retinol-binding protein 4 , cytokeratine 18 , hyaluronic acid) $[62,63]$ as indicators of hepatic histological damage, or clinical-laboratory scores as indicators of prognostic risk is not recommended in the clinical practice [64, 65] (LOEV-D).

Non-invasive investigations (magnetic resonance, computed tomography, elastography, ultrasound elastography)
[66] are promising but again their use is not recommended. (LOE V-D).

NAFLD may be screened also in overweight children presenting with waist-to-height ratio $>0.5$ and the assessment yearly repeated [67].

\section{Gallstones \\ There is no evidence to recommend the screening for colelithiasis. LOE IV-C}

Gallstone disease occurs in approximately $2 \%$ obese children and adolescents $[68,69]$. The rate increases up to $5.9 \%$ in obese patients with rapid weight loss [70]. The disease is rarely diagnosed, since it is symptomatic only in $20 \%$ cases $[69,71]$ In the presence of pain, primarily in the right upper quadrant, nausea and vomiting, assessment of serum transaminases, gamma glutamil transpherase, alkaline phosphatase, bilirubin and liver ultrasonography are diagnostic [71-73].

\section{Gastroesophageal reflux \\ Gastroesophageal reflux is suspected in the presence of evocative symptoms (such as pyrosis, heartburn, regurgitation). LOE VI-B}

The prevalence of gastroesophageal reflux in obese children and adolescents is 13-25\% (diagnosis made through questionnaires) [74-78]. Suggestive symptoms are pyrosis, epigastralgia, regurgitation. Weight loss may improve these symptoms. However, if symptoms persist or more severe symptoms occur (dysphagia, vomit) despite weight loss, referral for specialist investigations (gastrointestinal contrast study, endoscopy and oesophageal $\mathrm{pH}$ or impedance monitoring) and treatment is required [79].

\section{Polycystic ovary syndrome}

The components of the polycystic ovary syndrome should be considered in all female adolescents with obesity. LOE VI-A

Polycystic ovary syndrome (PCOS) is characterized by hyperandrogenism (acne, hirsutism and alopecia) and ovary dysfunction (oligo-amenorrhea). It is associated with increased risk of infertility, T2D, metabolic syndrome and cardiovascular disease in adulthood [80, 81]. In adult women, the diagnosis is based on at least two of the following criteria: a) oligo-ovulation and/or anovulation; b) clinical and/or biochemical signs of hyperandrogenism; c) polycystic ovary [82]. Since there is no widely accepted definition for PCOS in the teenage, it is suggested to identify and treat the single components of the syndrome [83]. Referral for specialist investigations is required to exclude other hyperandrogenic causes (congenital adrenal hyperplasia, androgen-secreting tumors, Cushing syndrome/disease) [80-84]. 


\section{Respiratory complications \\ Respiratory symptoms and signs should be sought in children and adolescents with obesity. LOE V-A}

The prevalence of respiratory problems, such as asthma, obstructive sleep apnea syndrome (OSAS), and obesity hypoventilation syndrome (OHS) is higher in obese children and adolescents compared to the general population $[85,86]$. OSAS affects $13-59 \%$ of obese children [85, 87-89]. The severity is strongly associated with excess weight, while adeno-tonsillar hypertrophy, skull-facial abnormalities, Afro-American and Asian ethnicities are modulation factors [85, 90]. The OHS is less frequent, affecting $3.9 \%$ obese patients [89].

Children and adolescents may present with increased breath rate, dyspnea after moderate efforts, wheezing, chest pain. OSAS is associated with intermittent hypoxemia, hypercapnia, and disrupted sleep. Specific symptoms and signs are: snoring/noisy breathing (> 3 nights/ week), pauses in breathing, mouth breathing, awakening headache that may persist during the day, daytime sleepiness, inability to concentrate, poor academic performance, hyperactivity, cognitive deficits. Rarely, growth delay, systemic hypertension pulmonary and artery hypertension have been reported in severe obesity $[91,92]$.

OHS is characterized by severe obesity, chronic daytime alveolar hypoventilation (defined as $\mathrm{PaCO}_{2}$ levels $>45 \mathrm{mmHg}$ and $\mathrm{PaO} 2<70 \mathrm{mmHg}$ ), a pattern of combined obstruction and restriction, in absence of other pulmonary, neuromuscular, metabolic, or chest diseases that may justify daytime hypercapnia [89].

In the presence of respiratory symptoms/signs, transcutaneous saturation of $\mathrm{O}_{2}$ should be determined; for values $<95 \%$, arterial blood emogasalysis should be performed. If asthma and/or any other ventilatory dysfunction are suspected, respiratory function (spirometry, pletismography, six minute walking test) should be measured. Allergological evaluation is not necessary, unless a history of atopia is reported [86], neither is necessary measuring the exhaled nitric oxide [93, 94]. Night polysomnography is the gold standard for diagnosis of sleep disorders. The apnea/hypopnea index (ratio between total number of apnea/hypopnea episodes and duration of sleep in hours) indicates the severity (1-5 very mild; 5-10 mild; 10-20 moderate; 20 severe). Alternatively, overnight pulse oximetry can be used, which is very specific but less sensitive. Otorhinolaryngoiatric or odontoiatric evaluations complete the diagnostic work-up. Cardiology referral should be considered in severe and long-lasting OSAS for assessing lung or systemic hypertension, and left ventricular hypertrophy [91]. Cognitive assessement may be required to assess neurocognitive damage and behavioral disorders [95].
Orthopaedic complications

Orthopaedic complications should be sought in the presence of musculoskeletal pain and joint limit ation at the lower extremity. LOE $V-A$

Severity of obesity and sedentary lifestyle influence the morphology of osteo-cartilaginous structures and growth plate, leading to serious orthopedic consequences [96, 97]. The main orthopaedic complications are: slipped capital femoral epiphysis, Blount's disease or tibia vara, valgus knee, flat foot [98-103].

Slipped capital femoral epiphysis may affect one or both hips; it usually occurs during the pubertal growth spurt. Hip pain and/or knee pain, an acute or insidious onset of a limp and decreased range of motion in the affected hip are the main symptoms/signs [104]. Blount disease is characterized by the varus deformity of the leg. Clinical manifestation is the instability of the knee in walking and lateral movements, simulating lameness [100]. Valgum knee is characterized by the deformity of the femoro-tibial angle in valgism; other deformities are associated, such as deviations in rotation of the tibia $[101,102]$. Flat foot is characterized by flattening of the medial arch and heel valgus. Pain may be reported along the medial part of the foot, with more specific complaints after exercises or long walks [105].

\section{Although obesity may exhibit higher risk of fracture, the measurement of bone density is not recommended. LOE V-D} The risk of fracture is increased in obese children, even for low energy injuries [106-108]. Inactivity, abnormalities in biomechanics of locomotion, inadequate balance may expose the obese child to fall and consequently to fracture, especially of the forearm [109]. There is no evidence that obesity results in a reduction of bone density [110]: while some studies have described an increased or normal bone mineral content, others reported a reduced bone mass in relation to bone size and weight [107].

\section{Renal complications}

There is insufficient evidence to recommend screening of kidney complications in non-diabetic and non-hypertensive children and adolescents with obesity. LOE IV-D

In adults, obesity is an independent risk factor for chronic kidney disease [111]. Obesity complication, (i.e. hypertension, dyslipidemia, insulin resistance, T2D, inflammatory state, autonomous system dysfunction) indeed, can alter the kidney function [112]. Peculiar to obesity, the obesity-related glomerulopathy is a secondary form of segmental focal glomerulosclerosis occurring tipically in obese patients and that improves after weight loss [112].

Obesity is likely to be a risk factor for chronic renal disease in children too. Indeed, children with renal disease have BMI higher than healthy population [113] and 
kidneys transplanted from obese donors have reduced glomerular filtration and higher rate of dysfunction than the kidneys obtained from normal weight donors [114]. In the light of current evidence [115-119], the assessment of microalbuminuria is not recommended in non-diabetic and non-hypertensive obese children (LOE IV-D). Individual cases of severe obesity $(\mathrm{BMI}>40)$ that may be associated with proteinuria in the nephrotic range remain to be evaluated individually (LOE VI-C).

\section{Idiopathic endocranic hypertension \\ Headache, vomiting, photophobia, transiently blurred vision, diplopia should be sought in subjects with overweight/obesity, especially if adolescents. LOE V-A}

Idiopathic endocranial hypertension is rare but potentially serious condition that can cause permanent loss of vision [120-122]. Prevalence and risk of recurrence increase with the severity of BMI [123-125]. Some symptoms occur frequently in adolescents as in adults (headache, vomiting, photophobia, transiently blurred vision, diplopia), while irritability, apathy, drowsiness, dizziness, cervical and dorsal pain are less frequent [123, 126]. The diagnosis is based on the presence of increased intracranial pressure documented with a lumbar puncture, papilledema, normal neurologic examination results (except for cranial nerves), normal cerebrospinal fluid composition, normal appearance of neuroimaging studies, and no other identifiable cause of increased intracranial pressure [127].

\section{Migraine and chronic headache}

\section{Promoting healthy lifestyle habits and weight control can} be a protective factor of migraine and chronic headache. LOE $V$-B

Recent studies have reported greater risk of episodic or recurrent migraine or daily chronic headache or tension headache in obese children and adolescents than the normal population [128, 129]. Some drugs used for headache and migraine have weight gain as side effect [129]. Negative lifestyle factors, which may influence the prevalence of recurrent headache, are possible targets for preventive measures [130]. An intervention study reported improvement in migraine symptoms after weight loss [131].

\section{Psychosocial correlates}

Psychosocial discomfort may affect therapeutic success, therefore it should be identified as part of the multidisciplinary assessment. LOE V-A

Recognition of psycho-social correlates (unsatisfactory body image, depressive and anxiety symptoms, loss of eating control, weight concern, dysfunctional social relationships, inactivity due to problematic body image, obesity-related stigma, low self-esteem, academic failure) is crucial to promoting specific strategies that improve the results in weight loss programs [132-134]. Although obesity is not a psychopathological and behavioral disorder, referral for specialist consult is needed in the suspicious of depressive and/ or anxious symptoms, dysmorphophobic traits, suicidal risk, and eating disorders $[135,136]$.

\section{Binge eating disorder \\ The presence of binge eating disorder should be considered in the multi-professional assessment of an obese child or adolescent. LOE V-B}

Binge Eating Disorder (BED) is the most common Nutrition and Eating Disorder found in pediatric obesity. It is indicative of psychopathology and is a serious risk factor for the development of obesity, especially in the presence of family history of obesity and marked negative experiences coupled with factors predisposing to psychiatric disorders [137]. BED is often preceeded by uncontrolled eating since childhood, occasional bulimia, obesity, but also by an attention deficit and hyperactivity disorder [136-138]. Upon referral to appropriate medical subspecialists and/or mental health personnel, the diagnosis of BED is critical to the therapeutic success. It may be necessary associating psychological and pharmacological therapy (only in selected cases) within the weight-loss treatment program $[136,137,139]$.

\section{Treatment}

Changes in diet and lifestyle leading to a negative caloric balance is recommended to gradually reduce the BMI. LOE I-A

The main objective is a permanent change in the child's eating habits and lifestyle, rather than attaining rapid weight loss through low-calorie diets. It is indispensable involving the whole family and setting realistic goals.

Further goals:

- maintaining an appropriate growth rate and achieving an healthier weight-to-height ratio;

- reducing weight excess (without necessarily achieving the ideal weight), in particular the fat mass, while preserving the lean mass;

- maintaining or promoting good mental health (self-esteem, correct attitudes toward food and body image, health related quality of life);

- treatment and improvement/resolution of complications, if present, in the shortest time possible;

- achieving and mantaining a healthier weight-to-height ratio and preventing relapses.

Diet

A balanced and varied diet is recommended (LOE I-A)

The classic diet-therapy based on the prescription of a low calorie diet is not effective in the medium/long term 
with relapses and failures, increased risk of dropout and progression into more complicated forms [140] (LOE III-B).

The educational process starts from the assessment of the child's and family's dietary habits, by means of the assessment of meal composition, portions, frequency of food intake, food preferences or aversions, use of condiments, cooking methods and food presentation [141-145] (LOE I-A).

Food diary is an excellent tool for assessing eating behavior; it should be compiled by the child together with the parents or by the adolescent and evaluated by the operator [146, 147] (LOE I-B).

\section{Dietary advice}

1. Eat 5 meals a day (three meals and no more than two snacks) [148] (LOE V-B)

2. Have an adequate breakfast [149] (LOE II-B)

3. Avoid eating between meals [150] (LOE III-B)

4. Avoid high-energy and low nutrient density foods (eg. sweetened or energizing drinks, fruit juices, fast food, high-energy snack) [151, 152] (LOE III-B)

5. Increase intake of fruit, vegetables and fiber rich cereals [153, 154] (LOE VI-A)

6. Limit portions $[155,156]$ (LOE I-A)

If a hypocaloric diet is needed, it should fulfill the National Recommended Energy and Nutrient Intake Levels, based on sex, age and ideal weight for stature (proteins $1 \mathrm{~g} / \mathrm{kg} /$ day; carbohydrates $45-60 \%$ of total calories; simple sugars $<15 \%$ of total calories, lipids $20-35 \%$ of total calories starting from 4 years of age, saturated fatty acids $<10 \%$ of total calories) [157] (LOE VI-A).

\section{Efficacy of dietary regimens}

There are currently no randomized controlled trials (RCTs) examining the effects of different diets on child's weight and body composition, regardless of potential confounders such as treatment intensity, behavioral or physical activity strategies [158, 159].

\section{Very low caloric diet}

It is the most effective regimen in terms of weight loss [160]. One example is the protein-sparing modified fast (600-800 kcal/day, protein $1.5-2 \mathrm{~g} / \mathrm{kg}$ ideal weight, carbohydrates 20-25 g/day, multivitamins + minerals, water $>2000 \mathrm{ml} /$ day), which can be prescribed in selected patients with severe obesity, under close medical surveillance and in specialized pediatric centers. The aim is to induce rapid weight loss (duration of this restrictive diet no longer than 10 weeks) followed by a less restrictive diet regimen balanced in macronutrients. RCTs are not available to evaluate medium to long-term efficacy compared to other diet-therapies and possible adverse effects on growth (LOE III-C).

\section{Traffic light and modified traffic light diets}

Reduced caloric intake (1000-1500 kcal/day) is achieved trough categories of foods grouped by nutrient density [161]. They were found to produce a significant improvement of BMI in 8-12 year old children even in the long term [162] (LOE III-C).

\section{Non-restrictive approach}

It does not consider a given caloric intake or nutrient composition, rather it focuses on the consumption of low-fat and high-nutrient density foods (LOE III-C).

\section{Replacement meals}

They are not recommended, since efficacy and safety have not been tested in children/adolescents.

No significant effect has been demonstrated for diets with specific macronutrient composition and medium caloric content in children. In particular:

\section{Hypocaloric diets with low glycemic index and low glycemic load}

Although an effect on satiety is suggested, their superiority compared with other dietary approaches has not been proved over the medium term [163-165] (LOE I-C).

\section{Exercise}

It is recommended to associate physical exercise to diet. LOE I-A

Physical exercise ameliorates body composition and reduces cardio-metabolic risk factors. [166-171]. Change in body composition (in particular fat reduction) rather than reduced BMI is sensitive to evaluating the effectiveness of exercise [166, 172].

It has not yet been proven which is the ideal exercise for obese children [170]. Low evidence demonstrates that combining aerobic and resistance exercises results in fat mass reduction, especially with programs of at least 2 weekly sessions and duration $>60 \mathrm{~min}$ [173] (LOE I-B).

The evidence is limited that exercising at higher intensity is more effective in modifying the body composition (LOE I-B). Owing to difficulty of obese subjects to practice exercise at high intensity, there is no evidence that vigorus efforts result in greater body fat reduction [166]. Children and adolescents should practice $60 \mathrm{~min}$ or more of physical activity every day, which should be mainly represented by aerobic exercises at least of moderate intensity; resistance exercises are suggested for at least 3 times a week, adjusted to the physical abilities of the obese child [174, 175]. Examples of aerobic and resistance 
exercises for obese children and adolescents are synthetized in Table 6. The practice of recreational activities and sports that involve a large amount of body mass such as swimming, soccer, basketball, volleyball, handball, rugby or require anaerobic and neuromuscular power, such as gymnastics or judo is encouraged. In severe obesity exercises that put constant weight or repeated impact on the child's legs, feet and hips should be avoided.

\section{Sedentary behaviors}

It is suggested to reduce the time spent in sedentary behaviours (television viewing, videogaming, internet surfing). LOE II-B

Weight gain may be only partially due to sedentary behaviors [176-179]; in the case of television viewing, it may be associated with overfeeding [180]. Interventions targeting sedentary behaviour were more effective in children aged 5-12 years [181].

Use of active video games may be suggested to increase daily energy expenditure in obese and sedentary children. LOE I-B Active video games represent an additional strategy to reduce sedentary behaviors. They do not replace 'real' sports activities, but can contribute to increase energy expenditure beyond the sedentary activity threshold, provided they are supervised by adults [182-187].

\section{The systematic use of active video games for weight loss and} improvement of body composition is not discouraged. LOE III-C While studies are not consistent with the recommendation to use active video games to obtain weight loss or improve body composition, their use is not recommended but neither discouraged to obtain other effects (improvement in vascular response, heart rate and $\mathrm{VO}_{2 \max }$ or obesity-related comorbidities; positive psycho-behavioral and psycho-social effects) [182-184].

\section{Cognitive and family-based behavioral therapy} Cognitive behavioral treatment or family-based behavioral treatment are both recommended to favor better adhesion to diet and physical activity. Cognitive behavioral treatment LOE III- B; family-based behavioral treatment LOE I- A

Cognitive behavioral techniques are effective. Neverthless, they are not easily applicable requiring specific training of the multidisciplinary team [188-

Table 6 Examples of aerobic and resistance exercises suggested for obese children and adolescents

\begin{tabular}{|c|c|}
\hline $\begin{array}{l}\text { Aerobic } \\
\text { exercises }^{a}\end{array}$ & $\begin{array}{l}\text { exercises on treadmill, cycle ergometer, elliptical trainer } \\
\text { water activities (swimming or water aerobics) }\end{array}$ \\
\hline $\begin{array}{l}\text { Resistance } \\
\text { exercises }^{a}\end{array}$ & $\begin{array}{l}\text { body weight exercise (push-ups, sit-ups, abdominal } \\
\text { crunches), lifting free weights, using weight training } \\
\text { machines and elastic resistance bands, circuit training }\end{array}$ \\
\hline
\end{tabular}

ander qualified supervision
190]. The most effective techniques are goal setting, self-monitoring (through food and physical activity diaries), contingency training, stimulus control, positive reinforcement, cognitive restructuring, problem solving [191].

Family-based behavioral treatments involve multicomponent interventions aimed at changing the lifestyle of the whole family, with goals shared between parents and children [191-194]. Interventions in which parents are active participants are more effective than interventions in which they are not encouraged to make their own behavioral changes. On the other hand, family-based therapies require greater investment of resources in terms of time and staff involved [188, 190, 192-198]. In children, they are more effective than treatments not involving parents. There is no robust evidence demontsrating their superiority in adolescents $[189,190,194]$ (LOE I-A).

Therapeutic education has been proposed in the recent years, using tools of cognitive-behavioral approach and motivational interview, such as reflective listening, therapeutic alliance, family approach, modeling, motivational counseling, narrative approach, positive reinforcement, goal setting, negotiating treatment objectives. It requires professional skills of all the team members with ongoing training [199-201] (LOE VI-B).

Child Appetite Awareness Training and Cue Exposure Treatment are still considered experimental and require further studies [202, 203] (LOE V-C).

\section{Indicators of successful treatment The BMI standard deviation score is recommended to estimate weight loss. LOE V-B}

The reduction of the BMI Standard Deviation Score (BMI-SDS) is the best indicator of the weight loss amount taking into account the patient's age and gender [204]. A reduction $>0.5$, but even $>0.25$ (consistent with a $1 \mathrm{~kg} / \mathrm{m}^{2}$ BMI reduction or stable weight for more than 1 year in a growing child) was associated with improved body composition and decreased cardio-metabolic risk [205].

Waist circumference and waist/height ratio can be used to monitor abdominal fat variations but are subject to error and offer no benefit over BMI [204, 206-208]. The same is true for the skinfold thicknesses $[204,209]$.

Other behavioral indicators (related to diet, lifestyle, physical fitness or quality of life) can be considered if no substantial reduction in the BMI-SDS occurs. LOE VI-B

Since the percentage of weight loss is generally low, evaluation based solely on the BMI-SDS may induce a sense of failure in the family and healthcare workers. In order to maintain the adherence to treatment, a stable modification of diet, physical activity and sedentary behavior, the increase of physical fitness and improvement 
of the quality of life should be considered as index of good compliance [210, 211].

\section{The scarce effect of treatment in the long term demands the development of long-lasting care models and their validation. LOE VI-B}

The effectiveness of treatment programs based on diet and lifestyle on BMI-SDS reduction was shown only in the short term (6-12 months) $[167,212]$. In a European multicentre study, the success rate (BMI SDS reduction $>0.25$ ) was $7 \%$ at 2 years; it reached $50 \%$ in a few number of centers, which differed for the greater intensity of intervention and training of the multi-disciplinary team $[213,214]$. Only two national studies based on diet education, cognitive or cognitive-behavioral strategies and family involvement reported BMI-SDS reduction of 0.44 after three years [199] and 1.49 after 5 years of follow up [188], respectively.

\section{It is necessary to monitor the possible onset of eating} disorders, especially when the weight loss is rapid. LOE IV-A Dissatisfaction with body image may be related to the onset of eating disorders, especially bulimia nervosa and binge eating, but also of anorexia nervosa [215-218]. Diet education undertakings can accentuate the perceived stigma in subjects with obesity, causing drastic strategies of weight control $[219,220]$. In some cases, the onset is triggered by an initially desired restriction of food, which then becomes uncontrollable. Careful evaluation of excessive weight variations and related bodily experience, especially when hypocaloric diets are prescribed, is recommended [217-219, 221].

\section{Pharmacological intervention}

Pharmacological therapy can only be applied after the failure of the multidisciplinary lifestyle intervention. LOE VI-B

When clinically significant weight loss cannot be achieved through lifestyle-based interventions, use of drugs is considered, especially in severe obesity with cardiometabolic, hepatic or respiratory disorders [222-226]. Management of drugs should be done in specialist centers [225].

\section{Orlistat is the only drug available for the treatment of} children and adolescents with severe obesity age. LOE II-B Few studies, with small sample size and short duration, are available on the effects of anti-obesity medications in pediatric age [227-230]. Orlistat (tetra-hydro-lipstinate) is the only drug approved for the treatment of obesity in pediatric age. It seems producing significant weight loss and favoring behavioral changes [231-233]. It does not affect the mineral balance, if the low-calorie diet is associated with normal mineral content; on the contrary, attention must be paid to prevent liposoluble vitamins deficiency [234].

\section{Bariatric surgery}

Bariatric surgery is the ultimate solution in adolescents with severe obesity and resistant to all other treatments, especially when serious complications are present. LOE VI-B The indications for surgery in the adolescent are (LOE III-B) [235, 236]:

- $\quad$ BMI $\geq 35 \mathrm{~kg} / \mathrm{m}^{2}$ with at least one severe comorbidity, such as T2D, moderate to severe obstructive sleep apnea (AHI > 15), idiopathic endocranial hypertension, NAFLD with significant fibrosis (Ishak score $>1$ ).

- $\quad$ BMI $\geq 40 \mathrm{~kg} / \mathrm{m}^{2}$ with less serious comorbidities, such as mild sleep apnea (apnea/hypopnea index $>5$ ), hypertension, dyslipidemia, carbohydrate intolerance.

More prudently other guidelines suggest a BMI > $40 \mathrm{~kg} / \mathrm{m}^{2}$ with one severe comorbidity or $>50 \mathrm{~kg} / \mathrm{m}^{2}$ with less serious comorbidities [223, 237].

Eligibility criteria are: adolescents with long lasting severe obesity; a. previous failure of any dietetic, behavioral or pharmacological intervention (after at least 12 months of intensive treatment); b. family and social support in managing the multidisciplinary care programs; c. decisional capacity for surgical management and the post-surgery follow-up; $d$. able to express the informed assent.

\section{Surgery should be performed in a highly specialized center that guarantees the presence of an experienced multidisciplinary team. LOE III-A}

The multidisciplinary team carefully evaluates the case and poses the indication for the surgey taking care of the pre-surgical assessment and post-surgical follow-up $[238,239]$. The preoperative phase includes a comprehensive assessment of the patient and the family, with particular regard to physical and psychological maturation of the adolescent and his/her adherence to treatment [235, 237, 240]. Neuropsychiatric counseling should be undertaken to identify cases at risk of psychotic disorders, severe major depression, personality or eating disorders, alcoholism and drug dependence [235-237]. In the postoperative follow-up anthropometric, clinical and nutritional assessment, and counseling are performed and early or late complications are monitored.

For the adverse effect on height velocity, the adolescent should have reached adequate skeletal maturation or a pubertal stage IV according to Tanner $[223,236$, 237, 241] (LOE III-A).

Contraindications to surgery are documented substance abuse problem and/or drug dependencies; patient inability to care for him/herself or to participate in life-long medical follow-up, no long-term family or social support that will warrant such care and follow-up; acute or chronic diseases 
even not directly associated with obesity threatening life in the short term; high anesthetic risk; pregnancy or planned pregnancy within the first two years after surgery, current breast-feeding [237] (LOE VI-A).

\section{Indication for surgery must be given on a case-by-case basis by the multidisciplinary team (LOE VI-A)}

Surgical procedures performed mostly by laparoscopy in adolescents and supported by at least 3 years of follow-up, are: a. restrictive interventions, including adjustable gastric bandage and sleeve gastrectomy; b. restrictive/malabsorbitive interventions, such as Roux-en $\mathrm{Y}$ gastric by-pass (RYGB) (LOE III-B).

Although the RYGB is the gold standard, there is no enough evidence to support this specific surgical technique compared to the others in terms of effectiveness, side effects, long-term complications and benefits [239]. Although studies in adolescents have increased, lack of RCTs makes it difficult to establish the effective efficacy at this age. There is no evidence or expert opinion supporting the efficacy of anticipating bariatric surgery to the teenage with respect to adults. A recent Cochrane review identified four RCTs in progress with expected results in the near future [242]. Several non-randomized and non-controlled trials were published with at least three years follow-up on the use of bariatric surgery in adolescents [243-247]. The published studies showed an average BMI decrease of $16.6 \mathrm{~kg} / \mathrm{m}^{2}$ after RYGB, $11.6 \mathrm{~kg} / \mathrm{m}^{2}$ after gastric bandage and $14.1 \mathrm{~kg} / \mathrm{m}^{2}$ after sleeve gastrectomy [248]. All interventions have been associated with improvement or complete restoration of comorbidities. Most studies are consistent in demonstrating improvement of the quality of life [244, 248-250].

\section{Care settings}

For the multifactorial nature of obesity, variability in its severity, and the health implications, treatment should be conducted in multiple settings with different levels of treatment. LOE III-A

Health services should be organized in a network of services [150, 251-254]. Fundamental is the periodic training of all network operators on motivational counseling, parenting and teamwork [251]. A child- and family-centered approach is based on sharing simple and realistic objectives about eating habits, sedentary behaviours, physical activity, and verification of results related to improving nutritional status, quality of life and complications if present [255-258].

\section{Primary care pediatricians represent the first level treatment. LOE III-A}

Primary care pediatricians' responsibilities are summarized in Table 7 [259, 260]. They are the reference point for obese children/adolescents and their family, participating in the various proposals for action and decisions, when a more aggressive approach is proposed (e.g., hospitalization or surgery). The efficacy of obesity treatment in the primary care setting is still modest [261, 262], but it might improve if pediatricians are assisted by other professionals experienced in pediatric obesity (dieticians/nutritionist, psychologist) and trained in family education and interdisciplinary work [258, 259, 263, 264] (LOE VI-B).

\section{District or hospital outpatient services represent the second level of care. LOE VI-A}

In the second level centers, the multidisciplinary team (pediatrician, dietician and psychologist) experienced in pediatric obesity defines the clinical condition of children referred by the primary care pediatricians, and runs the multidisciplinary intervention that is centered on diet education and lifestyle modification [150, 260, 265, 266]. The patient is referred to the third level health care center in case of no response to the treatment, severe comorbidities, compromised psychological balance or significantly impaired quality of life.

\section{Specialized centers for pediatric obesity represent the third level of care. LOE VI-A}

Third level centers are organized on a multidisciplinary and multiprofessional basis for comorbidity management or bariatric surgery. They admit patients who are suspected of secondary obesity or require more specialistic diagnostic assessment and/or intensive care programs, including bariatric surgery. They coordinate the networking activities as well as the training of operators and promote research activities and intervention trials in the context of specific protocols [267-271].

\section{Transition}

Pediatric obesity care should include a transition path from pediatric to adult care. LOE VI-B

It is necessary to test a transition model for adolescents with severe obesity and/or complications, particularly with metabolic syndrome, NAFLD, hypertension [272-274]. Unfortunately, the experience is extremely limited for the high drop-out, poor consideration about obesity as chronic illness, absence of pre-established pathways, possible transition to structures that follow the specific complications (eg. hypertension), no availability of cost-effective models [275].

\section{Prevention}

Given the multifactorial nature of obesity, preventive interventions should be designed to modify the environmental and social determinants. Health and non-health professionals should be involved in implementing healthy food education and promoting physical activity. Promotion of balanced nutrition and healthy lifestyle implies the need to remodel economic, agricultural, 
Table 7 Primary care pediatricians' responsibilities

\begin{tabular}{|c|c|}
\hline Conditions & Responsabilities \\
\hline $\begin{array}{l}\text { Risk factors: } \\
\text { Prenatal life: first-degree familiarity for obesity, low socioeconomic status; } \\
\text { Neonatal life: small for gestational age, or macrosomic infant; } \\
\text { Postnatal life: no breastfeeding, early complementary feeding, excessive } \\
\text { weight gain in the first two years of life, early adiposity rebound }\end{array}$ & $\begin{array}{l}\text { Monitoring the child's weight and length linear growth } \\
\text { Educating to a balanced diet and healthy lifestyle since the } \\
\text { earliest years of life } \\
\text { Assuring appropriate timing of complementary feeding }\end{array}$ \\
\hline $\begin{array}{l}\text { Children and adolescents with overweight or moderate, } \\
\text { uncomplicated obesity }\end{array}$ & $\begin{array}{l}\text { Early identification of children's excess weight } \\
\text { Promoting parental awareness of children's excess weight } \\
\text { Motivating and supporting the family to change, possibly } \\
\text { involving other professionals trained in childhood obesity }\end{array}$ \\
\hline $\begin{array}{l}\text { Severe obesity or psychological co-morbidity, or additional risk factors, } \\
\text { or biochemical alterations, or treatment failure within } 4-6 \text { months }\end{array}$ & $\begin{array}{l}\text { Identification of severe obesity } \\
\text { Promoting parental awareness of children's excess weight } \\
\text { Motivating and supporting the family to more intensive levels of care }\end{array}$ \\
\hline Suspicion of secondary obesity & Referral to specialized centers \\
\hline
\end{tabular}

industrial, environmental, socio-educational, recreational and health policies, including those aimed at contrasting socio-economic and ethnic minorities' inequalities [276]. To be effective, actions must be multicomponent and multilevel, building agreements and alliances among many stakeholders, including families, community organizations such as schools and sport institutions, health care providers [277-279]. Primary prevention actions begin from the prenatal age, involving the "Birth Pathway" within the family counselling services, spanning to the adolescence with actions spread at individual, family and community levels [260].

\section{Prevention is based on behavioral modification starting from the prenatal age. LOE I-A}

Lifestyle-based interventions are able to achieve mild but significant effects on dysfunctional behaviors (diet, physical activity, sedentary behaviours) and BMI [280]. Maintaining the BMI in a growing child is an important health objective. The best results have been obtained in school settings and in children 6-12 years [263]. Further studies are needed to determine the effectiveness of preventive interventions in children under 3 years and adolescents [281].

The family involvement is strongly recommended. LOE III-A Similarly to treatment, preventive interventions involving the whole family are recommended as more successful and long lasting compared to child-centered interventions, though they were more effective in children than adolescents [263, 282-284]. Interventions targeting at specific behaviors, such as taking fruits and vegetables and reducing sedentary behaviours have been found effective as well [283].

\section{Prenatal age}

Women should start pregnancy with appropriate weight and control their weight gain following an healthy lifestyle. LOE III-A

An excessive weight gain during pregnancy is associated with fetal macrosomy and increased risk of obesity
[285-290]. This effect is independent of maternal hyperglycemia, which is also a well-known risk factor for future obesity [291]. Recommended gestational weigh gain is between 11.5 and $16 \mathrm{Kg}$ in normal weight women, 7 to $11.5 \mathrm{Kg}$, in overweight and 5 to $9 \mathrm{Kg}$ in those who with prepregnancy obesity [292].

\section{Tobacco smoke in pregnancy is banned. LOE III-A}

Maternal smoking in the perinatal age increased the risk of overweight at age 7 regardless of birth weight; the risk increased for maternal smoking not only in pregnancy but also in the post-natal period. There was a dose-dependent effect. Hence, smoking exposure must be banned in preand post-natal life [293, 294].

\section{Diet}

\section{First two years of life}

Avoid excessive weight gain and/or increased weight-tolength ratio from the very first months of life. LOE III-A

Early rapid weight gain increases the risk of overweight and obesity in childhood [295]. Prevention in infants is focused on quality, quantity and timing of food intake. In particular:

Exclusive breastfeeding is recommended up to 6 months [296-299]. LOE III-A.

Solid foods and beverages other than breast milk or infant formulas should be introduced no earlier than 4 months and no later than 6 months [300-305]. LOE III-B.

Protein intake should be limited to less than $15 \%$ of the daily energy intake [302, 306-309]. LOE I-B.

Reduction of lipid intake to percentages indicated for adults is not recommended [310]. LOE II-D.

Sweetened drinks should be avoided [311]. LOE III-A.

There is insufficient evidence that complementary responsive feeding practices, such as baby-led weaning (which is associated with early satiety-responsiveness acquisition), are protective against obesity respect to usual complementary feeding mode [312-314]. LOE V-C. 
From preschool age to adolescence

Low energy density diet is recommended, based on the principles of the Mediterranean diet, promoting at least 5 servings of fruit and vegetables and plant based proteins [315]. Food should be distributed in no more than 5 daily meals and household consumption of meals should be promoted [316, 317]. LOE V-A.

The use of fast food and fast food-based venues should be limited [318, 319].LOE V-A.

Avoid sweetened drinks, including sports drinks and juice additives; alcoholic and energy drinks should also be avoided in adolescents [320-322]. LOE I-A.

\section{Physical activity}

It is recommended that children/adolescents spend on average $60 \mathrm{~min}$ a day on moderate/vigorous physical activity. LOE III-A

Prospective studies have shown a negative association between levels of physical activity and overweight/obesity [323, 324]. Even moderate physical activity is sufficient to improve aerobic fitness, an important marker of metabolic health which is independent of adiposity [325, 326]. 210, 211 Moderate physical activity is more effective and easier to implement in children who are sedentary or overweight. The increase of physical activity levels can be achieved starting from the age of 2-3 years by active play, walking, using the tricycle, and after 5-6 years, promoting also sports participation 2/3 times a week. Exercise should primarily stimulate aerobic capacity, but also strength and flexibility, be adequate to the child's ability and stage of physical and psychomotor development [174, 175, 327].

\section{Sedentary behaviours}

The use of television and electronic games is discouraged in children $<2$ years of age. LOE VI-B

Although there are no specific studies on the effects of video exposure on overweight/obesity in this age group, video exposure should be discouraged since it may disturb sleep regularity [328, 329].

\section{Sedentary behavior, especially the time spent in front of a screen (TV, video games, computers, mobile phones, etc.) should be reduced to less than $2 h$ a day in children $>2$ years of age. $L O E$ III-B}

The association between sedentary behaviour, obesity and cardiometabolic risk factors is weak, and it is reduced when corrected for physical activity levels [330]. On the contrary, the evidence based on prospective studies and RCTs show a strong relationship between television hours, obesity and cardio-metabolic risk factors, presumably because overfeeding frequently occurs [331, 332].

Several studies demonstrated a greater amount of television hours in children who have a television in their bedroom, but there is no clear evidence that its removal reduces the duration of the video exposure [333]; on the contrary the installation of an electronic television time manager seems effective [334]. Decreasing sedentary behavior was more successful in reducing BMI in children 5-12 years [181]. Prospective studies showed that interrupting prolonged sedentary periods with mild physical activity had beneficial effects on metabolic outcomes in adults [335]. Although evidence is lacking in pediatric age, it is suggested breaking up prolonged sitting time at home and school.

\section{Sleep duration and quality}

Adequate sleep duration and quality should be promoted in infants, children and adolescents. LOE III-B

A short sleep duration is a potential risk factor for overweight/obesity through neuroendocrine and metabolic influences [336, 337]. One meta-analysis of longitudinal studies indicated a risk of obesity more than doubled in children with a sleep duration lower than recommended [338]. Three intervention studies aimed at changing sleeping hours within a multicomponent obesity treatment were not effective in reducing the BMI [339]. Waiting for stronger evidence, we endorse the recommendation for optimal amount of sleep in children and adolescents released by the American Academy of Sleep Medicine [340] syntethized in Table 8. Turning off all "screens" 30 min before bedtime is also suggested to ensuring adequate sleep.

Involvement of school settings for implementing preventive actions

It is recommended to include the school settings in obesity prevention programs. LOE I-A

The school is institutionally devoted to the education of children and is certainly a privileged area for the implementation of preventive actions. Studies support with moderate/high evidence that promoting healthy nutrition and physical activity at school prevent excessive weight gain and reduce the prevalence of overweight/ obesity [341, 342]. The most effective and promising changes are summarized in Table 9. [334].

Table 8 Recommended amount of sleep in children and adolescents

\begin{tabular}{ll}
\hline $4-12$ months & $12-16 \mathrm{~h} /$ day (including afternoon naps) \\
$1-2$ years & $11-14 \mathrm{~h} /$ day (including afternoon naps) \\
$3-5$ years & $10-13 \mathrm{~h} /$ day (including afternoon naps) \\
$6-12$ years & $9-12 \mathrm{~h} /$ day \\
$13-18$ years & $8-10 \mathrm{~h} /$ day \\
\hline
\end{tabular}


Table 9 Effective environmental strategies to prevent pediatric obesity at school

Support school personnel's strategies for implementing health
promotion programs.
Improvement of overall school food environment:
Removal of vending machines selling sugar sweetened beverages or
snacks high in fat, sugar or salt; banning sales of this kind of food;
reformulation of school lunches to reduce high calorie unhealthy food.
Provision of a healthy breakfast
Provision of free or low-cost fruit
Provision of free/low cost water
Improvement of overall school physical activity environment:
Increase of the daily formal PA session organized during and
after school hours.
Availability of school playgrounds for structured/unstructured
PA during and after regular school hours

\section{Conclusions}

This paper is a Consensus position document on the care of pediatric obesity in children and adolescents produced by experts belonging to the Italian Society for Pediatric Endocrinology and Diabetology and the Italian Society of Pediatrics, and endorsed by the main Italian scientific societies involved in tackling obesity and its complications.

Consistent evidences suggest that the disease-burden of obesity on the overall health starts very early in life and is particularly serious for the development of cardiometabolic disease risk factors during childhood and adolescence and the association with premature mortality in adults. Furthermore, the mechanical and psychosocial comorbidities undermine physical functioning and the health-related quality of life. Several systematic reviews and meta-analyses on treatment and prevention indicate that weight control may be obtained by multicomponent intervention focused on a life-long change in the child's eating habits and lifestyle, involving the whole family and the surrounding social environment (school, communities). The effectiveness of treatment programs based on diet and lifestyle on excess weight reduction was shown only in the short term. Further study is needed to evaluate the effectiveness and safety of the different modalities of treatment, including pharmacotherapy and/or bariatric surgery, in the long term.

\section{Additional file}

Additional file 1: Level of evidence and grade of recommendations according to the National Guidelines System [4]. (DOCX 15 kb)

\footnotetext{
Abbreviations

BED: Binge eating disorder; BMl: Body mass index; BP: Blood pressure; DBP: Diastolic blood pressure; HbA1c: Hemoglobin glycosilated A1c; HDLC: HDL-cholesterol; IGT: Impaired glucose tolerance; LOE: Level of evidence; NAFLD: Non-alcoholic fatty liver disease; OGT: Oral glucose tolerance test; OHS: Obesity hypoventilation syndrome; OSAS: Obstructive sleep apnea syndrome; PCOS: Polycystic ovary syndrome; RCTs: Randomized controlled trials; RYGB: Roux-en Y gastric by-pass; SBP: Systolic blood pressure; SDS: Standard deviation score; T2D: Type 2 diabetes; TG: Triglycerides; WHO: World Health Organization
}

\section{Acknowledgments}

The authors thank F. Cerutti, Past President of the Italian Society for Pediatric Endocrinology and Diabetology, G. Corsello, Past President of the Italian Society of Pediatrics, S. Cianfarani, President of the Italian Society for Pediatric Endocrinology and A. Villani, President of the Italian Society of Pediatrics for their support to the realization of this document.

\section{Authors' contributions}

All the authors reviewed the articles on the literature and contributed to the first draft of specific sections of the manuscript, under the supervision and the coordination of GV, GS and CM; GV, MM and CM revised the final draft All authors read and approved the final manuscript. The following members of Childhood Obesity Study Group of the Italian Society of Pediatric Endocrinology and Diabetology contributed to the discussion through meetings and electronic communications and approved the content of this Consensus: Vanessa Bianchi (Pisa); Adriana Bobbio (Aosta); Mariella Bruzzese (Locri, Reggio Calabria), Carmen Buongiovanni (Monteforte Irpino, Avellino), Pietro Buono (Napoli), Annalisa Calcagno (Genova), Giuliano Cuccarolo (Venezia), Osvaldo D’Amico (Salerno), Elena De Nitto (Napoli), Grazia Filannino (Ostuni, Brindisi), Franco Francesca (Udine), Daniela Galeazzi (Narni, Terni), Lia Franca Giusti (Lucca), Antonella Gualtieri (Avezzano, L'Aquila), Riccardo Lera (Alessandria), Sonia Lucchesi (Livorno), Elisabetta Modestini (Atri, Teramo), Enza Mozzillo (Napoli), Laura Nanni (Pistoia), Maria Chiara Pellegrin (Trieste), Sonia Peruzzi (Lecce), Paola Peverelli (Belluno), Barbara Predieri (Modena), Ivana Rabbone (Torino), Maria Carolina Salerno (Napoli), Stefano Stagi (Firenze), Maura Sticco (San Prisco, Caserta), Gianluca Tornese (Trieste), Pietro Yiannakou (Albano Laziale, Roma). This article was also approved by Presidents of the following Pediatric scientific societies and associations: A. Caretto (Associazione Italiana di Dietetica e Nutrizione Clinica); C. Catassi (Società Italiana di Gastroenterologia Epatologia e Nutrizione Pediatrica); G. Chiamenti (Italian Federation of Pediatricians Federazione Italiana Medici Pediatri); G. Di Mauro (Società Italiana di Pediatria Preventiva e Sociale); P. Garofalo (Società Italiana di Medicina dell'Adolescenza); M. Picca (Società Italiana delle Cure Primarie); E. Riva (Società Italiana di Nutrizione Pediatrica); P. Sbraccia (Società Italiana di Obesità); F. Zanetto (Associazione Culturale Pediatri).

\section{Ethics approval and consent to participate}

Not applicable.

\section{Consent for publication}

Not applicable

\section{Competing interests}

The authors declare that they have no competing interests.

\section{Publisher's Note}

Springer Nature remains neutral with regard to jurisdictional claims in published maps and institutional affiliations.

\section{Author details}

${ }^{1}$ Department of Movement Sciences and Wellbeing, University of Naples Parthenope, via Medina 40, 80133 Naples, Italy. ${ }^{2}$ Pediatric Diabetes and Metabolic Disorders Unit, University of Verona, Verona, Italy. ${ }^{3}$ Department of Pediatrics, University Hospital of Pisa, Pisa, Italy. ${ }^{4}$ Italian Society of Pediatrics (SIP), Rome, Italy. ${ }^{5}$ Department of Medical and Surgical Sciences, University Hospital S.Orsola-Malpighi, Bologna, Italy. ${ }^{6}$ Department of Health Sciences, University of Piemonte Orientale, Novara, Italy. ${ }^{7}$ Local health unit, Ferrara, Italy. ${ }^{8}$ Italian Society for Pediatric Endocrinology and Diabetology (SIEDP), Parma, Italy. ${ }^{9}$ Pediatrics Unit, University of Pavia and Fondazione IRCCS Policlinico San Matteo, Pavia, Italy. ${ }^{10}$ Local health unit Roma 2, Rome, Italy. ${ }^{11}$ Italian Society for Obesity (SIO), Francavilla Fontana (Brindisi), Italy. ${ }^{12}$ Chair of Pediatrics, University of Chieti, Chieti, Italy. ${ }^{13}$ Pediatric Unit, Hospital of Gallipoli, Gallipoli (Lecce), Italy. ${ }^{14}$ Autoimmune Endocrine Diseases Unit, Bambino Gesù Children Hospital, IRCCS, Rome, Italy. ${ }^{15}$ Department of Internal Medicine, "S. Maria delle Grazie", Pozzuoli Hospital, Naples, Italy.

${ }^{16}$ Department of Pediatrics, ARNAS "Civico-Di Cristina-Benfratelli", Palermo, Italy. ${ }^{17}$ Pediatric and Neonatal Unit, "G. Mazzini"Hospital, Teramo, Italy. ${ }^{18}$ Department of Woman, Child and General and Specialized Surgery, University of Campania "Luigi Vanvitelli", Naples, Italy. ${ }^{19}$ Artificial Nutrition Unit Bambino Gesù, Children's Hospital, IRCCS, Rome, Italy. ${ }^{20}$ Italian 
Federation of Pediatricians (FIMP), Venice, Italy. ${ }^{21}$ Endocrinology and Diabetology Unit Bambino Gesù Children Hospital, IRCCS, Rome, Italy. ${ }^{22}$ Pediatric Unit, S. Chiara Hospital, Trento, Italy. ${ }^{23}$ Department of Translational Medical Science, Regional Center for Pediatric Diabetes, University Federico II of Naples, Naples, Italy. ${ }^{24}$ Azienda Tutela della Salute (ATS), Milan, Italy. ${ }^{25}$ Division of Auxology, Istituto Auxologico Italiano, IRCCS, Verbania, Italy. ${ }^{26}$ Pediatric Unit, University of Modena and Reggio Emilia, Modena, Italy. ${ }^{27}$ Italian Federation of Pediatricians (FIMP), Teramo, Italy. ${ }^{28}$ Department of Neurosurgery and Rehabilitation, AORN Santobono Pausilipon, Naples, Italy. ${ }^{29}$ Local health unit Napoli 3 sud, Torre del Greco (Naples), Italy. ${ }^{30}$ Research Area for Multifactorial Diseases, Children's Hospital Bambino Gesù, Rome, Italy. ${ }^{31}$ Istituto Ortopedico Rizzoli, Bologna, Italy. ${ }^{32}$ Pediatric Unit, "Infermi" Hospital, Rimini, Italy. ${ }^{33}$ Pediatric Diabetes and Metabolic Disorders Unit, University Hospital of Verona, Verona, Italy. ${ }^{34}$ Nutrition Unit, Bambino Gesù Children's Hospital IRCCS, Rome, Italy. ${ }^{35}$ Local health unit (AULSS) 6 Euganea, Padova, Italy. ${ }^{36}$ Department of Pediatrics and Infantile Neuropsychiatry, Sapienza University of Rome, Rome, Italy. ${ }^{37}$ Hepatometabolic Unit, Bambino Gesù Children's Hospital, IRCSS, Rome, Italy. ${ }^{38}$ Pediatric Unit, Verona University Medical School, Verona, Italy. ${ }^{39}$ Italian Federation of Pediatricians (FIMP), Catania, Italy. ${ }^{40}$ Pediatric obesity Unit, ASP of Ragusa, Ragusa, Italy. ${ }^{41}$ Oasi Research Institute -IRCCS, Troina (Ragusa), Italy. ${ }^{42}$ Department of Obstetrics, Gynaecology and Paediatrics, Arcispedale S.Maria Nuova-IRCCS, Reggio Emilia, Italy. ${ }^{43}$ Italian Society for Pediatric Endocrinology and Diabetology (SIEDP), Ferrara, Italy. ${ }^{44}$ Pediatric Unit, ASST-Rhodense, Rho (Milan), Italy. ${ }^{45}$ Deparment of Pediatrics, San Paolo Hospital, University of Milan, Milan, Italy. ${ }^{46}$ Department of Social Sciences, University of Naples Federico II, Naples, Italy.

Received: 8 January 2018 Accepted: 7 June 2018

Published online: 31 July 2018

\section{References}

1. Spinelli A, Nardone P, Buoncristiano M, Lauria L, Pierannunzio D. Centro nazionale per la prevenzione delle malattie e la promozione della salute, Cnapps-Iss. OKkio alla Salute: i dati nazionali. 2016; http://www.epicentro.iss. it/okkioallasalute/dati2016.asp

2. Valerio G, Licenziati MR, Manco M, et al. Health consequences of obesity in children and adolescents. Minerva Pediatr. 2014;66:381-414.

3. Società Italiana di Pediatria Obesità del bambino e dell'adolescente: Consensus su prevenzione, diagnosi e terapia. Argomenti di Pediatria 1/06 Milano: Istituto Scotti Bassani; 2006.

4. Programma nazionale Linee Guida Manuale metodologico. Come produrre, diffondere e aggiornare raccomandazioni per la pratica clinica. Maggio. 2002. http://old.iss.it/binary/lgmr2/cont/Manuale_PNLG.1234439852.pdf.

5. WHO Multicentre Growth Reference Study Group. WHO child growth standards based on length/height, weight and age. Acta Paediatr Suppl. 2006;450:76-85.

6. de Onis M, Onyango AW, Borghi E, Siyam A, Nishida C, Siekmann J. Development of a WHO growth reference for school-aged children and adolescents. Bull WHO. 2007:85:660-7.

7. Cacciari E, Milani S, Balsamo A, et al. Italian cross-sectional growth charts for height, weight and BMI (2 to 20 yr). J Endocrinol Investig. 2006;29:581-93.

8. Valerio G, Balsamo A, Baroni MG, et al. Childhood obesity classification systems and cardiometabolic risk factors: a comparison of the Italian, World Health Organization and international obesity task force references. It J Pediatr. 2017:43(Suppl 1):19.

9. Barlow SE, Expert Committee. Recommendations regarding the prevention, assessment and treatment of child and adolescent overweight and obesity: summary report. Pediatrics. 2007;120(Suppl 4):S164-92.

10. de Onis M, Lobstein T. Defining obesity risk status in the general childhood population: which cut-offs should we use? Int J Pediatr Obes. 2010;5:458-60.

11. de Onis M, Martínez-Costa C, Núñez F, Nguefack-Tsague G, Montal A, Brines J. Association between WHO cut-offs for childhood overweight and obesity and cardiometabolic risk. Public Health Nutr. 2013;16:625-30.

12. Kelly AS, Barlow SE, Rao G, Inge TH, Hayman LL, Steinberger J, Urbina EM, Ewing $L$, Daniels SR, American Heart Association Atherosclerosis, Hypertension, and Obesity in the Young Committee of the Council on Cardiovascular Disease in the Young, Council on Nutrition, Physical Activity and Metabolism, and Council on Clinical Cardiology. Severe obesity in children and adolescents: identification, associated health risks, and treatment approaches: a scientific statement from the American Heart Association. Circulation. 2013;128:1689-712.

13. Martos-Moreno GÁ, Barrios V, Muñoz-Calvo MT, Pozo J, Chowen JA, Argente J. Principles and pitfalls in the differential diagnosis and management of childhood obesities. Adv Nutr. 2014;5:2995-305S.

14. Mason K, Page L, Balikcioglu PG. Screening for hormonal, monogenic, and syndromic disorders in obese infants and children. Pediatr Ann. 2014;43:e218-24.

15. Angulo MA, Butler MG, Cataletto ME. Prader-Willi syndrome: a review of clinical, genetic, and endocrine findings. J Endocrinol Investig. 2015;38:1249-63.

16. Khan SA, Muhammad N, Khan MA, Kamal A, Rehman ZU, Khan S. Genetics of human Bardet-Biedl syndrome, an updates. Clin Genet. 2016;90:3-15.

17. Marshall JD, Muller J, Collin GB, et al. Alström syndrome: mutation spectrum of ALMS1. Hum Mutat. 2015;36:660-8.

18. Douzgou S, Petersen MB. Clinical variability of genetic isolates of Cohen syndrome. Clin Genet. 2011;79:501-6.

19. Mangelsdorf M, Chevrier E, Mustonen A, Picketts DJ. Börjeson-ForssmanLehmann syndrome due to a novel plant homeodomain zinc finger mutation in the PHF6 gene. J Child Neurol. 2009;24:610-4.

20. Twigg SR, Lloyd $D$, Jenkins $D$, et al. Mutations in multidomain protein MEGF8 identify a carpenter syndrome subtype associated with defective lateralization. Am J Hum Genet. 2012;91:897-905.

21. Basil JS, Santoro SL, Martin $\sqcup$, Healy KW, Chini BA, Saal HM. Retrospective study of obesity in children with Down syndrome. J Pediatr. 2016;173:143-8.

22. Bojesen A, Kristensen K, Birkebaek NH, et al. The metabolic syndrome is frequent in Klinefelter's syndrome and is associated with abdominal obesity and hypogonadism. Diabetes Care. 2006;29:1591-8.

23. Calcaterra V, Brambilla P, Maffè GC, et al. Metabolic syndrome in turner syndrome and relation between body composition and clinical, genetic, and ultrasonographic characteristics. Metab Syndr Relat Disord. 2014;12:159-64.

24. Albuquerque D, Stice E, Rodríguez-López R, Manco L, Nóbrega C. Current review of genetics of human obesity: from molecular mechanisms to an evolutionary perspective. Mol Gen Genomics. 2015;290:1191-21.

25. Huvenne H, Dubern B, Clément K, Poitou C. Rare genetic forms of obesity: clinical approach and current treatments in 2016. Obes Facts. 2016;9:158-73.

26. Genovesi S, Antolini L, Giussani M, et al. Hypertension, prehypertension, and transient elevated blood pressure in children: association with weight excess and waist circumference. Am J Hypertens. 2010;23:756-61.

27. Friedemann C, Heneghan C, Mahtani K, Thompson M, Perera R, Ward AM. Cardiovascular disease risk in healthy children and its association with body mass index: systematic review and meta-analysis. BMJ. 2012;345:e4759.

28. Lo JC, Chandra M, Sinaiko A, et al. Severe obesity in children: prevalence, persistence and relation to hypertension. Int J Pediatr Endocrinol. 2014;2014:3.

29. Rosner B, Cook NR, Daniels S, Falkner B. Childhood blood pressure trends and risk factors for high blood pressure: the NHANES experience 1988-2008. Hypertension. 2013;62:247-54.

30. Wirix AJ, Nauta J, Groothoff JW, et al. Is the prevalence of hypertension in overweight children overestimated? Arch Dis Child. 2016;101:998-1003.

31. Strambi M, Giussani M, Ambruzzi MA, et al. Novelty in hypertension in children and adolescents: focus on hypertension during the first year of life, use and interpretation of ambulatory blood pressure monitoring, role of physical activity in prevention and treatment, simple carbohydrates and uric acid as risk factors. Ital J Pediatr. 2016;42:69.

32. National High Blood Pressure Education Program Working Group on High Blood Pressure in Children and Adolescents. The fourth report on the diagnosis, evaluation, and treatment of high blood pressure in children and adolescents. Pediatrics. 2004;1 14:555-76.

33. Lurbe E, Agabiti-Rosei E, Cruickshank JK, et al. European Society of Hypertension guidelines for the management of high blood pressure in children and adolescents. J Hypertens. 2016;34:1887-920.

34. Spagnolo A, Giussani M, Ambruzzi AM, et al. Focus on prevention, diagnosis and treatment of hypertension in children and adolescents. Ital J Pediatr. 2013;39:20.

35. Estrada E, Eneli I, Hampl S, et al. Children's hospital association consensus statements for comorbidities of childhood obesity. Child Obes. 2014;10:304-17.

36. Di Bonito P, Moio N, Sibilio G, et al. Cardiometabolic phenotype in children with obesity. J Pediatr. 2014;165:1184-9.

37. Pieruzzi F, Antolini L, Salerno FR, et al. The role of blood pressure, body weight and fat distribution on left ventricular mass, diastolic function and cardiac geometry in children. J Hypertens. 2015;33:1182-92. 
38. American Diabetes Association. Classification and diagnosis of diabetes. Sec. 2. In standards of medical Care in Diabetes-2016. Diabetes Care. 2016; 39(Suppl. 1):S13-22.

39. Zhang $X$, Gregg EW, Williamson DF, et al. A1C level and future risk of diabetes: a systematic review. Diabetes Care. 2010;33:1665-73.

40. Kester LM, Hey H, Hannon TS. Using hemoglobin A1c for prediabetes and diabetes diagnosis in adolescents: can adult recommendations be upheld for pediatric use? J Adolesc Health. 2012;50:321-3.

41. Springer SC, Silverstein J, Copeland K, et al. Management of type 2 diabetes mellitus in children and adolescents. Pediatrics. 2013;131:e648-64.

42. Kapadia CR. Are the ADA hemoglobin a(1c) criteria relevant for the diagnosis of type 2 diabetes in youth? Curr Diab Rep. 2013;13:51-5.

43. Di Bonito P, Pacifico L, Chiesa C, et al. Impaired fasting glucose and impaired glucose tolerance in children and adolescents with overweight/ obesity. J Endocrinol Investig. 2017 Apr;40(4):409-16.

44. Maffeis C, Pinelli L, Brambilla P, et al. Fasting plasma glucose (FPG) and the risk of impaired glucose tolerance in obese children and adolescents. Obesity (Silver Spring). 2010;18:1437-42.

45. Bedogni G, Gastaldelli A, Manco M, et al. Relationship between fatty liver and glucose metabolsim: a cross-sectional study in 571 obese children. Nutr Metab Cardiovasc Dis. 2012;22:120-6.

46. Morandi A, Maschio M, Marigliano M, et al. Screening for impaired glucose tolerance in obese children and adolescents: a validation and implementation study. Pediatr Obes. 2014;9:17-25.

47. Manco M, Grugni G, Di Pietro M, et al. Triglycerides-to-HDL cholesterol ratio as screening tool for impaired glucose tolerance in obese children and adolescents. Acta Diabetol. 2016;53:493-8.

48. Korsten-Reck U, Kromeyer-Hauschild K, Korsten K, Baumstark MW, Dickhuth $\mathrm{HH}$, Berg A. Frequency of secondary dyslipidemia in obese children. Vasc Health Risk Manag. 2008;4:1089-94.

49. Casavalle PL, Lifshitz F, Romano LS, et al. Prevalence of dyslipidemia and metabolic syndrome risk factor in overweight and obese children. Pediatr Endocrinol Rev. 2014;12:213-23.

50. Morrison JA, Glueck CJ, Woo JG, Wang P. Risk factors for cardiovascular disease and type 2 diabetes retained from childhood to adulthood predict adult outcomes: the Princeton LRC follow-up study. Int J Pediatr Endocrinol. 2012;2012:6.

51. National Institutes of Health National Heart, Lung, and Blood Institute. Expert panel on integrated pediatric guideline for cardiovascular health and risk reduction in children and adolescents: summary report. Pediatrics. 2011; 128:S1-S446.

52. Peterson AL, McBride PE. A review of guidelines for dyslipidemia in children and adolescents. WMJ. 2012;111:274-81.

53. Campagna F, Martino F, Bifolco M, et al. Detection of familial hypercholesterolemia in a cohort of children with hypercholesterolemia: results of a family and DNA-based screening. Atherosclerosis. 2008;196:356-64.

54. Pacifico L, Bonci E, Andreoli G, et al. Association of serum triglyceride-to$\mathrm{HDL}$ cholesterol ratio with carotid artery intima-media thickness, insulin resistance and nonalcoholic fatty liver disease in children and adolescents. Nutr Metab Cardiovasc Dis. 2014:24:737-43.

55. Di Bonito P, Valerio G, Grugni G, et al. Comparison of non-HDL-cholesterol versus triglycerides-to-HDL-cholesterol ratio in relation to cardiometabolic risk factors and preclinical organ damage in overweight/obese children: the CARITALY study. Nutr Metab Cardiovasc Dis. 2015;25:489-94.

56. Di Bonito P, Moio N, Scilla C, et al. Usefulness of the high triglyceride-to-HDL cholesterol ratio to identify cardiometabolic risk factors and preclinical signs of organ damage in outpatient children. Diabetes Care. 2012;35:158-62.

57. Schwimmer JB, Deutsch R, Kahen T, Lavine JE, Stanley C, Behling C. Prevalence of fatty liver in children and adolescents. Pediatrics. 2006;118:1388-93.

58. Feldstein AE, Charatcharoenwitthaya P, Treeprasertsuk S, Benson JT, Enders $F B$, Angulo $P$. The natural history of non-alcoholic fatty liver disease in children: a follow-up study for up to 20 years. Gut. 2009;58:1538-44.

59. Schwimmer JB, Dunn W, Norman GJ, et al. SAFETY study: alanine aminotransferase cutoff values are set too high for reliable detection of pediatric chronic liver disease. Gastroenterology. 2010;138:1357-64. 1364.e1-2

60. Koot BG, van der Baan-Slootweg OH, Tamminga-Smeulders $\mathrm{CL}$, et al. Lifestyle intervention for non alcoholic fatty liver disease: prospective cohort study of its efficacy and factors related to improvement. Arch Dis Child. 2011;96:669-74.

61. Vajro $P$, Lenta $S$, Socha $P$, et al. Diagnosis of nonalcoholic fatty liver disease in children and adolescents: position paper of the ESPGHAN hepatology committee. J Pediatr Gastroenterol Nutr. 2012;54:700-13.
62. Nobili V, Alkhouri N, Alisi A, et al. Retinol-binding protein 4: a promising circulating marker of liver damage in pediatric nonalcoholic fatty liver disease. Clin Gastroenterol Hepatol. 2009;7:575-9.

63. Lebensztejn DM, Wierzbicka A, Socha $P$, et al. Cytokeratin-18 and hyaluronic acid levels predict liver fibrosis in children with non-alcoholic fatty liver disease. Acta Biochim Pol. 2011;58:563-6.

64. Alkhouri N, Mansoor S, Giammaria P, Liccardo D, Lopez R, Nobili V. The development of the pediatric NAFLD fibrosis score (PNFS) to predict the presence of advanced fibrosis in children with nonalcoholic fatty liver disease. PLoS One. 2014;9:e104558.

65. Marzuillo P, Grandone A, Perrone L, Miraglia Del Giudice E. Controversy in the diagnosis of pediatric non-alcoholic fatty liver disease. World J Gastroenterol. 2015:21:6444-50.

66. Goyal NP, Schwimmer JB. The progression and natural history of pediatric nonalcoholic fatty liver disease. Clin Liver Dis. 2016;20:325-38.

67. Maffeis C, Banzato C, Rigotti F, et al. Biochemical parameters and anthropometry predict NAFLD in obese children. J Pediatr Gastroentero Nutr. 2011;53:590-3.

68. Kaechele $\mathrm{V}$, Wabitsch $\mathrm{M}$, Thiere $\mathrm{D}$, et al. Prevalence of gallbladder stone disease in obese children and adolescents: influence of the degree of obesity, sex, and pubertal development. J Pediatr Gastroenterol Nutr. 2006; 42:66-70.

69. Mehta S, Lopez ME, Chumpitazi BP, Mazziotti MV, Brandt ML, Fishman DS Clinical characteristics and risk factors for symptomatic pediatric gallbladder disease. Pediatrics. 2012;129:e82-8.

70. Heida A, Koot BG, vd Baan-Slootweg OH, et al. Gallstone disease in severely obese children participating in a lifestyle intervention program: incidence and risk factors. Int J Obes. 2014;38:950-3.

71. Svensson J, Makin E. Gallstone disease in children. Semin Pediatr Surg. 2012; 21:255-65.

72. Koebnick C, Smith N, Black MH, et al. Pediatric obesity and gallstone disease J Pediatr Gastroenterol Nutr. 2012;55:328-33.

73. Fradin K, Racine AD, Belamarich PF. Obesity and synmptomatic cholelithiasis in childhood: epidemiologic and case-control evidence for a strong relationship. J Pediatr Gastroenterol Nutr. 2014;58:102-6.

74. Størdal K, Johannesdottir GB, Bentsen BS, Carlsen KC, Sandvik L. Asthma and overweight are associated with symptoms of gastro-oesophageal reflux. Acta Paediatr. 2006:95:1197-201.

75. Malaty HM, Fraley JK, Abudayyeh S, et al. Obesity and gastroesophageal reflux disease and gastroesophageal reflux symptoms in children. Clin Exp Gastroenterol. 2009;2:31-6.

76. Pashankar DS, Corbin Z, Shah SK, Caprio S. Increased prevalence of gastroesophageal reflux symptoms in obese children evaluated in an academic medical center. J Clin Gastroenterol. 2009;43:410-3.

77. Teitelbaum JE, Sinha P, Micale M, Yeung S, Jaeger J. Obesity is related to multiple functional abdominal diseases. J Pediatr. 2009;154:444-6.

78. Koebnick C, Getahun D, Smith N, Porter AH, Der-Sarkissian JK, Jacobsen SJ. Extreme childhood obesity is associated with increased risk for gastroesophageal reflux disease in a large population-based study. Int J Pediatr Obes. 2011;6:e257-63.

79. Davies I, Burman-Roy S, Murphy MS. Guideline development group. Gastrooesophageal reflux disease in children: NICE guidance. BMJ. 2015;350:g7703.

80. Rotterdam ESHRE/ASRM-sponsored PCOS consensus workshop group. Revised 2003 consensus on diagnostic criteria and long-term health risks related to polycystic ovary syndrome (PCOS). Hum Reprod. 2004;19:41-7.

81. Azziz R, Carmina E, Dewailly D, et al. Position statement: criteria for defining polycystic ovary syndrome as a predominantly hyperandrogenic syndrome: an androgen excess society guideline. J Clin Endocrinol Metab. 2006;91:4237-45.

82. Amsterdam ESHRE/ASRM-Sponsored 3rd PCOS Consensus Workshop Group. Consensus on women's health aspects of polycystic ovary syndrome (PCOS). Hum Reprod. 2012;27:14-24.

83. Carmina E, Oberfield SE, Lobo RA. The diagnosis of polycystic ovary syndrome in adolescents. Am J Obstet Gynecol. 2010;203:201-5.

84. Conway G, Dewailly D, Diamanti-Kandarakis E, et al. European survey of diagnosis and management of the polycystic ovary syndrome: results of the ESE PCOS special interest Group's questionnaire.; ESE PCOS special interest group. Eur J Endocrinol. 2014;171:489-98.

85. Santamaria F, Montella S, Pietrobelli A. Obesity and pulmonary disease: unanswered questions. Obes Rev. 2012;13:822-33.

86. Delgado J, Barranco P, Quirce S. Obesity and asthma. J Investig Allergol Clin Immunol. 2008;18:420-5. 
87. Verhulst $S L$, Aerts $L$, Jacobs $S$, et al. Sleep-disordered breathing, obesity, and airway inflammation in children and adolescents. Chest. 2008;34:1169-75.

88. Kang KT, Weng WC, Lee PL, Hsu WC. Central sleep apnea in obese children with sleep-disordered breathing. Int J Obes. 2014;38:27-31.

89. Boxer GH, Bauer AM, Miller BD. Obesity-hypoventilation in childhood. Am J Acad Child Adolesc Psychiatry. 1988;27:552-8.

90. Rosen CL. Clinical features of obstructive sleep apnea hypoventilation syndrome in otherwise healthy children. Pediatr Pulmonol. 1999;27:403-9.

91. American Academy of Pediatrics. Diagnosis and management of childhood obstructive sleep apnea syndrome. Pediatrics. 2012;130:713-56.

92. Gachelin E, Reynaud R, Dubus JC, Stremler-Le BN. Detection and treatment of respiratory disorders in obese children: obstructive sleep apnea syndrome and obesity hypoventilation syndrome. Arch Pediatr. 2015;22:908-15.

93. McLachlan CR, Poulton R, Car G, et al. Adiposity, asthma, and airway inflammation. J Allergy Clin Immunol. 2007:119:634-9.

94. Santamaria F, Montella S, De Stefano S, et al. Asthma, atopy, and airway inflammation in obese children. J Allergy Clin Immunol. 2007:120:965-7.

95. Vitelli O, Tabarrini A, Miano S, et al. Impact of obesity on cognitive outcome in children with sleep-disordered breathing. Sleep Med. 2015;16:625-30.

96. Wearing SC, Hennig EM, Byrne NM, Steele JR, Hills AP. Musculoskeletal disorders associated with obesity: a biomechanical perspective. Obes Rev. 2006;7:239-50

97. Chan G, Chen CT. Musculoskeletal effects of obesity. Curr Opin Pediatr. 2009;21:65-70

98. Bhatia NN, Pirpiris M, Otsuka NY. Body mass index in patients with slipped capital femoral epiphysis. J Pediatr Orthop. 2006;26:197-9.

99. Loder RT, Skopelja EN. The epidemiology and demographics of slipped capital femoral epiphysis. ISRN Orthop. 2011;2011:486512.

100. Sabharwal S. Blount disease: an update. Orthop Clin North Am. 2015;46:37-47.

101. Bout-Tabaku S, Shults J, Zemel BS, et al. Obesity is associated with greater valgus knee alignment in pubertal children, and higher body mass index is associated with greater variability in knee alignment in girls. J Rheumatol. 2015;42:126-33

102. Jankowicz-Szymanska A, Mikolajczyk E. Genu valgum and flat feet in children with healthy and excessive body weight. Pediatr Phys Ther. 2016; 28:200-6.

103. Stolzman S, Irby MB, Callahan AB, Skelton JA. Pes planus and paediatric obesity: a systematic review of the literature. Clin Obes. 2015;5:52-9.

104. Loder RT, Aronsson DD, Weinstein SL, Breur GJ, Ganz R, Leunig M. Slipped capital femoral epiphysis. Instr Course Lect. 2008:57:473-98.

105. Harris EJ, Vanore JV, Thomas $J$, et al. Diagnosis and treatment of pediatric flatfoot. J Foot Ankle Surg. 2004;43:341-73.

106. Taylor ED, Theim KR, Mirch MC, et al. Orthopedic complications of overweight in children and adolescents. Pediatrics. 2006;117:2167-74.

107. Lazar-Antman MA, Leet Al. Effects of obesity on pediatric fracture care and management. J Bone Joint Surg Am. 2012;94:855-61.

108. Valerio G, Gallè $F$, Mancusi $C$, et al. Prevalence of overweight in children with bone fractures: a case control study. BMC Pediatr. 2012;12:166.

109. Skaggs DL, Loro ML, Pitukcheewanont P, Tolo V, Gilsanz V. Increased body weight and decreased radial cross-sectional dimensions in girls with forearm fractures. J Bone Miner Res. 2001;16:1337-42.

110. Bachrach LK, Sills IN. Section on endocrinology. Bone densitometry in children and adolescents. Pediatrics. 2011;127:189-94.

111. Wang Y, Chen X, Song Y, Caballero B, Cheskin LJ. Association between obesity and kidney disease: a systematic review and meta-analysis. Kidney Int. 2008;73:19-33.

112. Savino A, Pelliccia P, Chiarelli F, Mohn A. Obesity-related renal injury in childhood. Horm Res Pædiatrics. 2010;73:303-11.

113. Filler G, Reimão SM, Kathiravelu A, Grimmer J, Feber J, Drukker A. Pediatric nephrology patients are overweight: 20 years' experience in a single Canadian tertiary pediatric nephrology clinic. Int Urol Nephrol. 2007:39:1235-40.

114. Espinoza R, Gracida C, Cancino J, Ibarra A. Effect of obese living donors on the outcome and metabolic features in recipients of kidney transplantation. Transplant Proc. 2006;38:888-9.

115. Burgert TS, Dziura J, Yeckel C, et al. Microalbuminuria in pediatric obesity: prevalence and relation to other cardiovascular risk factors. Int J Obes. 2006; 30:273-80

116. Hirschler V, Molinari C, Maccallini G, Aranda C. Is albuminuria associated with obesity in school children? Pediatr Diabetes. 2010;11:322-30.

117. Savino A, Pelliccia P, Giannini C, et al. Implications for kidney disease in obese children and adolescents. Pediatr Nephrol. 2011;26:749-58.
118. Franchini S, Savino A, Marcovecchio ML, Tumini S, Chiarelli F, Mohn A. The effect of obesity and type 1 diabetes on renal function in children and adolescents. Pediatr Diabetes. 2015;16:427-33.

119. Goknar N, Oktem F, Ozgen IT, et al. Determination of early urinary rena injury markers in obese children. Pediatr Nephrol. 2015;30:139-44.

120. Stevenson SB. Pseudotumor cerebri: yet another reason to fight obesity. J Pediatr Health Care. 2008;22:40-3.

121. Markey KA, Mollan SP, Jensen RH, Sinclair AJ. Understanding idiopathic intracranial hypertension: mechanisms, management, and future directions. Lancet Neurol. 2016;15:78-91.

122. Paley GL, Sheldon CA, Burrows EK, Chilutti MR, Liu GT, McCormack SE. Overweight and obesity in pediatric secondary pseudotumor cerebri syndrome. Am J Ophthalmol. 2015;159:344-52.

123. Brara SM, Koebnick C, Porter AH, Langer-Gould A. Pediatric idiopathic intracranial hypertension and extreme childhood obesity. J Pediatr. 2012;161:602-7.

124. Salpietro V, Chimenz R, Arrigo T, Ruggieri M. Pediatric idiopathic intracranial hypertension and extreme childhood obesity: a role for weight gain. J Pediatr. 2013;162:1084

125. Stiebel-Kalish H, Serov I, Sella R, Chodick G, Snir M. Childhood overweight or obesity increases the risk of IIH recurrence fivefold. Int J Obes. 2014;38: 1475-7.

126. Bassan H, Berkner L, Stolovitch C, Kesler A. Asymptomatic idiopathic intracranial hypertension in children. Acta Neurol Scand. 2008;118:251-5.

127. Friedman DI, Liu GT, Digre KB. Revised diagnostic criteria for the pseudotumor cerebri syndrome in adults and children. Neurology. 2013;81: 1159-65.

128. Ravid S, Shahar E, Schiff A, Gordon S. Obesity in children with headaches: association with headache type, frequency, and disability. Headache. 2013; 53:954-61.

129. Oakley CB, Scher Al, Recober A, Peterlin BL. Headache and obesity in the pediatric population. Curr Pain Headache Rep. 2014;18:416.

130. Robberstad L, Dyb G, Hagen K, Stovner LJ, Holmen TL, Zwart JA. An unfavorable lifestyle and recurrent headaches among adolescents: the HUNT study. Neurology. 2010;75:712-7.

131. Verrotti A, Agostinelli S, D'Egidio C, et al. Impact of a weight loss program on migraine in obese adolescents. Eur J Neurol. 2013:20:394-7.

132. Anderson SE, Cohen P, Naumova EN, Jacques PF, Must A. Adolescent obesity and risk for subsequent major depressive disorder and anxiety disorder: prospective evidence. Psychosom Med. 2007;69:740-7.

133. Roth B, Munsch S, Meyer A, Isler E, Schneider S. The association between mothers psychopatology, childrens' competences and psychopatological well-being in obese children. Eat Weight Disord. 2008;13:129-36.

134. Vander Wal JS, Mitchell ER. Psychological complications of pediatric obesity. Pediatr Clin N Am. 2011;58:1393-401.

135. Latzer $Y$, Stein D. A review of the psychological and familial perspectives of childhood obesity. J Eat Disord. 2013;1:7.

136. American Psychiatric Association. Diagnostic and Statistical Manual of Mental Disorders: Diagnostic and Statistical Manual of Mental Disorders, Fifth Edition. Arlington: American Psychiatric Association; 2013.

137. Glasofer DR, Tanofsky-Kraff M, Eddy KT, et al. Binge eating in overweight treatment-seeking adolescents. J Pediatr Psychol. 2007;32:95-105.

138. Sonneville KR, Calzo JP, Horton NJ, et al. Childhood hyperactivity/inattention and eating disturbances predict binge eating in adolescence. Psychol Med. 2015;22:1-10.

139. Amianto F, Ottone L, Abbate Daga G, Fassino S. Binge-eating disorder diagnosis and treatment: a recap in front of DSM-5. BMC Psychiatry. 2015;15:70.

140. Astrup A, Raben A, Geiker N. The role of higher protein diets in weight control and obesity-related comorbidities. Int J Obes. 2015;39:721-6.

141. Epstein LH, Valoski A, Wing RR, McCurley J. Ten-year follow-up of behavioral, family-based treatment for obese children. JAMA. 1990;264:2519-23.

142. Golan M, Weizman A. Familial approach to the treatment of childhood obesity: conceptual model. J Nutr Educ Behav. 2001;33:102-7.

143. Golan M, Crow S. Targeting parents exclusively in the treatment of childhood obesity: long-term results. Obes Res. 2004;12:357-61.

144. Hollands GJ, Shemilt I, Marteau TM, et al. Portion, package or tableware size for changing selection and consumption of food, alcohol and tobacco. Cochrane Database Syst Rev 2015; 9:CD011045.

145. Barlow SE, Expert Committee. Expert committee recommendations regarding the prevention, assessment, and treatment of child and adolescent overweight and obesity: summary report. Pediatrics. 2007; 120(Suppl 4):S164-92. 
146. Burrows TL, Martin RJ, Collins CE. A systematic review of the validity of dietary assessment methods in children when compared with the method of doubly labeled water. J Am Diet Assoc. 2010;110:1501-10.

147. Burke LE, Wang J, Sevick AM. Self-monitoring in weight loss: a systematic review of the literature. J Am Diet Assoc. 2011;111:92-102.

148. Jääskeläinen A, Schwab U, Kolehmainen M, Pirkola J, Järvelin MR, Laitinen J. Associations of meal frequency and breakfast with obesity and metabolic syndrome traits in adolescents of northern Finland birth cohort 1986. Nutr Metab Cardiovasc Dis. 2013;23:1002-9.

149. Schlundt DG, Hill JO, Sbrocco T, Pope-Cordle J, Sharp T. The role of breakfast in the treatment of obesity: a randomized clinical trial. Am J Clin Nutr. 1992;55:645-51.

150. Spear BA, Barlow SE, Ervin C, et al. Recommendations for treatment of child and adolescent overweight and obesity. Pediatrics. 2007;120(Suppl 4):S254-88.

151. James J, Thomas P, Cavan D, Kerr D. Preventing childhood obesity by reducing consumption of carbonated drinks: cluster randomised controlled trial. BMJ. 2004;328:1237.

152. Taveras EM, Gortmaker SL, Hohman KH, et al. Randomized controlled trial to improve primary care to prevent and manage childhood obesity: the high five for kids study. Arch Pediatr Adolesc Med. 2011;165:714-22.

153. Kovács E, Siani A, Konstabel K, et al. Adherence to the obesity-related lifestyle intervention targets in the IDEFICS study. Int J Obes. 2014;38(Suppl 2):S144-51.

154. Maximova K, Ambler KA, Rudko JN, Chui N, Ball GD. Ready, set, go! Motivation and lifestyle habits in parents of children referred for obesity management. Pediatr Obes. 2015;10:353-60.

155. Savage JS, Fisher JO, Marini M, Birch LL. Serving smaller age-appropriate entree portions to children aged 3-5 y increases fruit and vegetable intake and reduces energy density and energy intake at lunch. Am J Clin Nutr. 2012:95:335-41.

156. Birch LL, Savage JS, Fischer JO. Right sizing prevention. Food portion size effects on children's eating and weight. Appetite. 2015;88:11-6.

157. Società Italiana di Nutrizione Umana. Livelli di assunzione di riferimento di nutrienti ed energia per la popolazione italiana (LARN). IV Revisione. Milano: SICSS Editore; 2014.

158. Suskind RM, Sothern MS, Farris RP, et al. Recent advances in the treatment of childhood obesity. Ann N Y Acad Sci. 1993;699:181-99.

159. Academy of Nutrition and Dietetics. Pediatric weight management: dietary interventions. Summary for pediatric weight management evidence-based nutrition practice guidelines 2007. https://www.andeal.org/topic.cfm?menu= $5296 \&$ cat $=5633$

160. Sothern M, Udall JN, Suskind RM, Vargas A, Blecker U. Weight loss and growth velocity in obese children after very low calorie diet, exercise, and behavior modification. Acta Paediatr. 2000;89:1036-43.

161. Epstein LH, Squires S. The stoplight diet for children: an eight week program for parents and children. Boston: Little Brown \& Co; 1988.

162. Epstein LH, Paluch RA, Beecher MD, et al. Increasing healthy eating vs. reducing high energy-dense foods to treat pediatric obesity. Obesity (Silver Spring). 2008;16:318-26.

163. Esfahani A, Wong JM, Mirrahimi A, Villa CR, Kendall CW. The application of the glycemic index and glycemic load in weight loss: a review of the clinical evidence. IUBMB Life. 2011;63:7-13.

164. Kirk S, Brehm B, Saelens BE, et al. Role of carbohydrate modification in weight management among obese children: a randomized clinical trial. J Pediatr. 2012:161:320-7.

165. Mirza NM, Palmer MG, Sinclair KB, et al. Effects of a low glycemic load or a low-fat dietary intervention on body weight in obese Hispanic American children and adolescents: a randomized controlled trial. Am J Clin Nutr. 2013;97:276-85.

166. Atlantis E, Barnes EH, Singh MA. Efficacy of exercise for treating overweight in children and adolescents: a systematic review. Int J Obes. 2006:30:1027-40.

167. McGovern L, Johnson JN, Paulo R, et al. Clinical review: treatment of pediatric obesity: a systematic review and meta-analysis of randomized trials. J Clin Endocrinol Metab. 2008;93:4600-5

168. Janssen I, Leblanc AG. Systematic review of the health benefits of physical activity and fitness in school-aged children and youth. Int J Behav Nutr Phys Act. 2010;7:40

169. Brambilla P, Pozzobon G, Pietrobelli A. Physical activity as the main therapeutic tool for metabolic syndrome in childhood. Int J Obes. 2011;35: $16-28$.
170. Kelley GA, Kelley KS, Pate RR. Exercise and BMI in overweight and obese children and adolescents: a systematic review and trial sequential metaanalysis. Biomed Res Int. 2015;2015:704539.

171. Stoner L, Rowlands D, Morrison A, et al. Efficacy of exercise intervention for weight loss in overweight and obese adolescents: meta-analysis and implications. Sports Med. 2016;46:1737-51.

172. Ho M, Garnett SP, Baur LA, et al. Impact of dietary and exercise interventions on weight change and metabolic outcomes in obese children and adolescents: a systematic review and meta-analysis of randomized trials. JAMA Pediatr. 2013;167:759-68.

173. García-Hermoso A, Sánchez-López M, Martínez-Vizcaíno V. Effects of aerobic plus resistance exercise on body composition related variables in pediatric obesity: a systematic review and meta-analysis of randomized controlled trials. Pediatr Exerc Sci. 2015;27:431-40.

174. Strong WB, Malina RM, Blimkie CJ, et al. Evidence based physical activity for school-age youth. J Pediatr. 2005;146:732-7.

175. Janssen I. Physical activity guidelines for children and youth. Appl Physiol Nutr Metab. 2007;32:S109-21

176. LeBlanc AG, Spence JC, Carson V, et al. Systematic review of sedentary behaviour and health indicators in the early years (aged $0-4$ years). Appl Physiol Nutr Metab. 2012:37:753-72.

177. Velde SJT, van Nassau F, Uijtdewilligen L, et al. Energy balance-related behaviours associated with overweight and obesity in preschool children: a systematic review of prospective studies. Obes Rev. 2012;13:56-74.

178. de Rezende LF, Rodrigues Lopes M, Rey-López JP, Matsudo VK, Luiz OC. Sedentary behavior and health outcomes: an overview of systematic reviews. PLoS One. 2014;9:e105620.

179. Pearson N, Braithwaite RE, Biddle SJ, van Sluijs EM, Atkin AJ. Associations between sedentary behaviour and physical activity in children and adolescents: a meta-analysis. Obes Rev. 2014;15:666-75.

180. Pearson N, Biddle SJ. Sedentary behavior and dietary intake in children, adolescents, and adults a systematic review. Am J Prev Med. 2011;41:17888.

181. Azevedo LB, Ling J, Soos I, Robalino S, Ells L. The effectiveness of sedentary behaviour interventions for reducing body mass index in children and adolescents: systematic review and meta-analysis. Obes Rev. 2016;17:623-35.

182. Lamboglia CM, da Silva VT, de Vasconcelos Filho JE, et al. Exergaming as a strategic tool in the fight against childhood obesity: a systematic review. J Obes. 2013;2013:438364

183. Gao Z, Chen S. Are field-based exergames useful in preventing childhood obesity? A systematic review. Obes Rev. 2014;15:676-91.

184. McGuire S, Willems ME. Physiological responses during multiplay exergaming in young adult males are game-dependent. J Hum Kinet. 2015; 46:263-71.

185. Gribbon A, McNeil J, Jay O, Tremblay MS, Chaput JP. Active video games and energy balance in male adolescents: a randomized crossover trial. Am J Clin Nutr. 2015:101:1126-34.

186. McNarry MA, Mackintosh KA. Investigating the relative exercise intensity of exergames in prepubertal children. Games Health J. 2016:5:135-40.

187. Staiano AE, Marker AM, Beyl RA, Hsia DS, Katzmarzyk PT, Newton RL. A randomized controlled trial of dance exergaming for exercise training in overweight and obese adolescent girls. Pediatr Obes. 2017;12:120-8.

188. Vignolo M, Rossi F, Bardazza G, et al. Five year follow-up of a cognitivebehavioural lifestyle multidisciplinary programme for childhood obesity outpatient treatment. Eur J Clin Nutr. 2008:62:1047-57.

189. Valerio G, Licenziati MR, Tanas $R$, et al. Management of children and adolescents with severe obesity. Minerva Pediatr. 2012;64:413-31.

190. Altman M, Wilfley DE. Evidence update on the treatment of overweight and obesity in children and adolescents. J Clin Child Adolesc Psychol. 2015;44: 521-37.

191. Wilfley DE, Stein RI, Saelens BE, et al. Efficacy of maintenance treatment approaches for childhood overweight: a randomized controlled trial. JAMA. 2007;298:1661-73

192. West F, Sanders MR, Cleghorn GJ, Davies PS. Randomized clinical trial of a family-based lifestyle intervention for childhood obesity involving parents as the exclusive agents of change. Behav Res Ther. 2010:48:1170-9.

193. Boutelle KN, Cafri G, Crow SJ. Parent-only treatment for childhood obesity: a randomized controlled trial. Obesity. 2011;19:574-80.

194. Serra-Paya N, Ensenyat A, Castro-Viñuales I, et al. Effectiveness of a multicomponent intervention for overweight and obese children (Nereu program): a randomized controlled trial. PLoS One. 2015;10:e0144502. 
195. Ho M, Garnett SP, Baur L, et al. Effectiveness of lifestyle interventions in child obesity: systematic review with meta-analysis. Pediatrics. 2012;130: e1647-71.

196. Golan M, Kaufman V, Shahar DR. Childhood obesity treatment: targeting parents exclusively v. Parents and children. Br J Nutr. 2006;95:1008-15.

197. Epstein LH, Paluch RA, Wrotniak $B H$, et al. Cost effectiveness of family-based group treatment for child and parental obesity. Child Obes. 2014;10:114-21.

198. laccarino Idelson P, Zito E, Mozzillo E, et al. Changing parental style for the management of childhood obesity: a multi-component group experience. Int J Child Health Nutr. 2015;4:213-8.

199. Tanas R, Marcolongo R, Pedretti S, Gilli G. A family-based education program for obesity: a three-year study. BMC Pediatr. 2007;7:33.

200. Lagger G, Pataky Z, Golay A. Efficacy of therapeutic patient education in chronic diseases and obesity. Patient Educ Couns. 2010;79:283-6.

201. Albano MG, Golay A, Vincent DA, Cyril Crozet C, d'Ivernois JF. Therapeutic patient education in obesity: analysis of the 2005-2010 literature. Ther Patient Educ. 2012;4:S101-10.

202. Bloom T, Sharpe L, Mullan B, Zuccker N. A pilot evalutation of appetiteawareness training in the treatment of childhood overweight and obesity: a preliminary investigation. Int J Eat Dis. 2013;46:47-51.

203. Boutelle KN, Zucker N, Peterson CB, Rydell S, Carlson J, Harnack LJ. An intervention based on Schachter's externality theory for overweight children: the regulation of cues pilot. J Pediatr Psychol. 2014;39:405-17.

204. Bryant M, Ashton L, Brown J, et al. Systematic review to identify and appraise outcome measures used to evaluate childhood obesity treatment interventions (CoOR): evidence of purpose, application, validity, reliability and sensitivity. Health Technol Assess. 2014;18:1-380.

205. Reinehr T, Lass N, Toschke C, Rothermel J, Lanzinger S, Holl RW. Which amount of BMI-SDS reduction is necessary to improve cardiovascular risk factors in overweight children? J Clin Endocrinol Metab. 2016;101:3171-9.

206. Maffeis C, Banzato C, Talamini G, Obesity Study Group of the Italian Society of Pediatric Endocrinology and Diabetology. Waist-to-height ratio, a useful index to identify high metabolic risk in overweight children. J Pediatr. 2008; 152:207-13.

207. Taylor RW, Williams SM, Grant AM, Taylor BJ, Goulding A. Predictive ability of waist-to-height in relation to adiposity in children is not improved with age and sex-specific values. Obesity (Silver Spring). 2011;19:1062-8.

208. Brambilla P, Bedogni G, Heo M, Pietrobelli A. Waist circumference-to-height ratio predicts adiposity better than body mass index in children and adolescents. Int J Obes. 2013:37:943-6.

209. Hunt LP, Ford A, Sabin MA, Crowne EC, Shield JP. Clinical measures of adiposity and percentage fat loss: which measure most accurately reflects fat loss and what should we aim for? Arch Dis Child. 2007:92:399-403.

210. Finne E, Reinehr T, Schaefer A, Winkel K, Kolip P. Changes in self-reported and parent-reported health-quality of life in overweight children and adolescents participating in an outpatient training: findings from a 12month follow-up study. Health Qual Life Outcomes. 2013;11:1.

211. Kolotourou M, Radley D, Chadwick $P$, et al. Is BMI alone a sufficient outcome to evaluate interventions for child obesity? Child Obes. 2013;9:350-6.

212. Oude LH. Interventions for treating obesity in children. Cochrane Database Sys Rev. 2009;1:CD0001872.

213. Reinehr T, Kleber M, Toschke AM. Lifestyle intervention in obese children is associated with a decrease of the metabolic syndrome prevalence. Atherosclerosis. 2009:207:174-80.

214. Reinher T, Widhalm K, I'Allemand D, Wiegand S, Wabitsch M, Holl RW. Two year follow-up in 21.784 overweight children and adolescents with lifestyle intervention. Obesity. 2009;17:1196-9.

215. Fairburn CG, Welch SL, Doll HA, Davies BA, O'Connor ME. Risk factors for bulimia nervosa. A community-based case-control study. Arch Gen Psychiatry. 1997;54:509-17

216. Fairburn CG, Doll HA, Welch SL, Hay PJ, Davies BA, O'Connor ME. Risk factors for binge eating disorder: a community-based, case-control study. Arch Gen Psychiatry. 1998:55:425-32.

217. Hilbert A, Pikeb KM, Goldschmidtc AB, et al. Risk factors across the eating disorders. Psychiatry Res. 2014;220:500-6.

218. Swenne I. Influence of premorbid BMI on clinical characteristics at presentation of adolescent girls with eating disorders. BMC Psychiatry. 2016;16:81.

219. Lebow J, Sim LA, Kransdorf LN. Prevalence of a history of overweight and obesity in adolescents with restrictive eating disorders. J Adolesc Health. 2015;56:19-24
220. Golden NH, Schneider M, Wood C, AAP Commitee on nutrition. Preventing obesity and eating disorders in adolescents. Pediatrics. 2016;138:e20161649.

221. Sim LA, Lebow J, Billings M. Eating disorders in adolescents with a history of obesity. Pediatrics. 2013;132:e1026-30.

222. Speiser PW, Rudolph MC, Anhalt H, et al. Childhood obesity. J Clin Endocrinol Metab. 2005;90:1871-87.

223. August GP, Caprio S, Fennoy l, et al. Prevention and treatment of pediatric obesity: an endocrine society clinical practice guideline based on expert opinion. J Clin Endocrinol Metab. 2008;93:4576-99.

224. Lau DC, Douketis JD, Morrison KM, et al. 2006 Canadian clinical practice guidelines on the management and prevention of obesity in adults and children. CMAJ. 2007;176:S1-13.

225. National Health and Medical Research Council. Clinical practice guidelines for the management of overweight and obesity in adults, adolescents and children in Australia. Melbourne: National Health and Medical Research Council; 2013

226. Sherafat-Kazemzadeh R, Yanovski SZ, Yanovski JA. Pharmacotherapy for childhood obesity: present and future. J Obes. 2013;37:1-15.

227. Padwal R, Li SK, Lau DC. Long-term pharmacotherapy for overweight and obesity: a systematic review and meta-analysis of randomized controlled trials. Int J Obes Relat Metab Disord. 2003;27:1437-46.

228. Franz MJ, VanWormer JJ, Crain AL, et al. Weight-loss outcomes: a systematic review and meta-analysis of weight-loss clinical trials with a minimum 1year follow-up. J Am Diet Assoc. 2007;107:1755-67.

229. lughetti L, Berri R, China MC, Predieri B. Current and future drugs for appetite regulation and obesity treatment. Recent Pat Endocr, Metab Immune Drug Discovery. 2009;3:102-28.

230. lughetti L, China MC, Berri R, Predieri B. Pharmacological treatment of obesity in children and adolescent: present and future. J Obes. 2011;2011: 928165 .

231. Norgren S, Danielsson P, Jurold R, Lötborn M, Marcus C. Orlistat treatment in obese prepubertal children: a pilot study. Acta Paediatr. 2003;92:566-70.

232. McDuffie JR, Calis KA, Uwaifo Gl, et al. Efficacy of orlistat as adjunct to behavioral treatment in overweight African and Caucasian adolescents with obesity-related co-morbid conditions. J Pediatr Endocrinol Metab. 2004;17: 307-19.

233. Chanoine JP, Hampl S, Jensen C, et al. Effect of orlistat on weight and body composition in obese adolescents: a randomized controlled trial. JAMA. 2005;293:2873-83.

234. Zhi J, Moore R, Kanitra L. The effect of short-term (21-day) orlistat treatment on the physiologic balance of six selected macrominerals and microminerals in obese adolescents. J Am Coll Nutr. 2003;22:357-62.

235. Michalsky M, Reichard K, Inge T, Pratt J, Lenders C. American Society for Metabolic and Bariatric Surgery: ASMBS pediatric committee best practice guidelines. Surg Obes Relat Dis. 2012;8:1-7.

236. Fried M, Yumuk V, Oppert JM, et al. Interdisciplinary European guidelines on metabolic and bariatric surgery. Obes Surg. 2014;24:42-55.

237. Nobili V, Vajro P, Dezsofi A, et al. Indications and limitations of bariatric intervention in severely obese children and adolescents with and without nonalcoholic steatohepatitis: ESPGHAN hepatology committee position statement. J Pediatr Gastroenterol Nutr. 2015:60:550-61.

238. Thakkar RK, Michalsky MP. Update on bariatric surgery in adolescence. Curr Opin Pediatr. 2015;27:370-6.

239. Black JA, White B, Viner RM, Simmons RK. Bariatric surgery for obese children and adolescents: a systematic review and meta-analysis. Obesity Rev. 2013;14:634-44

240. Hofman B. Bariatric surgery for obese children and adolescents: a review of the moral challenges. BMC Medical Ethics. 2013;14:18.

241. Brei MN, Mudd S. Current guidelines for weight loss surgery in adolescents: a review of the literature. J Pediatr Health Care. 2014;28:288-94.

242. Ells LJ, Mead E, Atkinson G, et al. Surgery for the treatment of obesity in children and adolescents. Cochrane Database Syst Rev. 2015:6:CD011740.

243. Olbers T, Gronowitz E, Werling M, et al. Two-year outcome of laparoscopic roux-en-Y gastric bypass in adolescents with severe obesity: results from a Swedish Nationwide study (AMOS). Int J Obes. 2012;36:1388-95.

244. Alqahtani AR, Antonisamy B, Alamri H, Elahmedi M, Zimmerman VA. Laparoscopic sleeve gastrectomy in 108 obese children and adolescents aged 5 to 21 years. Ann Surg. 2012;256:266-73.

245. Lennerz BS, Wabitsch $M$, Lippert $H$, et al. Bariatric surgery in adolescents and young adults--safety and effectiveness in a cohort of 345 patients. Int J Obes. 2014;38:334-40 
246. Alqahtani A, Elahmedi M, Qahtani AR. Laparoscopic sleeve gastrectomy in children younger than 14 years: refuting the concerns. Ann Surg. 2016;263:312-9.

247. Inge TH, Courcoulas AP, Jenkins TM, et al. Weight loss and health status 3 years after bariatric surgery in adolescents. N Engl J Med. 2016;374:113-23.

248. Paulus GF, de Vaan LE, Verdam FJ, Bouvy ND, Ambergen TA, van Heurn LW. Bariatric surgery in morbidly obese adolescents: a systematic review and meta-analysis. Obes Surg. 2015;25:860-78.

249. Beamish AJ, Olbers T. Bariatric and metabolic surgery in adolescents: a path to decrease adult cardiovascular mortality. Curr Atheroscler Rep. 2015;17:53.

250. Manco M, Mosca A, De Peppo F, et al. The benefit of sleeve gastrectomy in obese adolescents on nonalcoholic steatohepatitis and hepatic fibrosis. Pediatr. 2016;180:31-7.

251. Dietz WH, Baur LA, Hall K, et al. Management of obesity: improvement of health-care training and systems for prevention and care. Lancet. 2015;385: 2521-33.

252. Fitch A, Fox C, Bauerly K, et al. Prevention and management of obesity for children and adolescents. Bloomington: Institute for Clinical Systems Improvement (ICSI); 2013.

253. National Clinical Guideline Centre (UK). Obesity: identification, assessment and management of overweight and obesity in children, young people and adults: partial update of CG43. In: NICE clinical guidelines, vol. 189. London: National Institute for Health and Care Excellence; 2014.

254. Ebbeling CB, Antonelli RC. Primary care interventions for pediatric obesity: need for an integrated approach. Pediatrics. 2015;135:757-8.

255. Tuah NA, Amiel C, Qureshi S, Car J, Kaur B, Majeed A. Transtheoretical model for dietary and physical exercise modification in weight loss management for overweight and obese adults. Cochrane Database Syst Rev. 2011;10:CD008066.

256. Borrello M, Pietrabissa G, Ceccarini M, Manzoni GM, Castelnuovo G. Motivational interviewing in childhood obesity treatment. Front Psychol. 2015;6:1732

257. Barnes RD, Ivezaj V. A systematic review of motivational interviewing for weight loss among adults in primary care. Obes Rev. 2015;16:304-18.

258. Resnicow K, McMaster F, Bocian A, et al. Motivational interviewing and dietary counseling for obesity in primary care: an RCT. Pediatrics. 2015;135: 649-57.

259. Sargent GM, Pilotto LS, Baur LA. Components of primary care interventions to treat childhood overweight and obesity: a systematic review of effect. Obes Rev. 2011;12:e219-35.

260. Daniels SR, Hassink SG. Committee in Nutrition. The role of the pediatrician in primary prevention of obesity. Pediatrics. 2015;136:e275-92.

261. Sim LA, Lebow J, Wang Z, Koball A, Murad MH. Brief primary care obesity interventions: a meta-analysis. Pediatrics. 2016;138:e20160149.

262. Mitchell TB, Amaro CM, Steele RG. Pediatric weight management interventions in primary care settings: a meta-analysis. Health Psychol. 2016; 35:704-13.

263. Seburg EM, Olson-Bullis BA, Bredeson DM, Hayes MG, Sherwood NE. A review of primary care-based childhood obesity prevention and treatment interventions. Curr Obes Rep. 2015;4:157-73.

264. Bhuyan SS, Chandak A, Smith P, Carlton EL, Duncan K, Gentry D. Integration of public health and primary care: a systematic review of the current literature in primary care physician mediated childhood obesity interventions. Obes Res Clin Pract. 2015;9:539-52

265. Ministero della Salute Piano d'indirizzo per la Riabilitazione. Gruppo di Lavoro sulla Riabilitazione. https://umw.sinpia.eu/atom/allegato/1447.pdf. 2011.

266. Viner RM, White B, Barrett T, et al. Assessment of childhood obesity in secondary care: OSCA consensus statement. Arch Dis Child Educ Pract Ed. 2012;97:98-105

267. Donini LM, Cuzzolaro M, Spera G, et al. Consensus. Obesity and eating disorders. Indications for the different levels of care. An Italian expert consensus document. Eating Weight Disord. 2010;15:1-31.

268. Ahnert J, Löffler S, Müller J, Lukasczik M, Brüggemann S, Vogel H. Paediatric rehabilitation treatment standards: a method for quality assurance in Germany. J Public Health Res. 2014;3:275.

269. Rank M, Wilks DC, Foley L, et al. Health-related quality of life and physical activity in children and adolescents 2 years after an inpatient weight-loss program. J Pediatr. 2014;165:732-7.

270. Sauer H, Krumm A, Weimer K, et al. PreDictor research in obesity during medical care - weight loss in children and adolescents during an INpatient rehabilitation: rationale and design of the DROMLIN study. J Eat Disord. 2014;2:7.
271. Grugni G, Licenziati MR, Valerio G, et al. The rehabilitation of children and adolescents with severe or medically complicated obesity. An ISPED expert opinion document. Eat Weight Disord. 2017;22:3-12.

272. Rosen DS, Blum RW, Britto M, Sawyer SM, Siegel DM. Transition to adult health care for adolescents and young adults with chronic conditions: position paper of the Society for Adolescent Medicine. J Adolesc Health. 2003;33:309-11.

273. Schwartz LA, Daniel LC, Brumley LD, Barakat LP, Wesley KM, Tuchman LK. Measures of readiness to transition to adult health care for youth with chronic physical health conditions: a systematic review and recommendations for measurement testing and development. J Pediatr Psychol. 2014;39:588-601.

274. Campbell F, Biggs K, Aldiss SK, et al. Transition of care for adolescents from paediatric services to adult health services. Cochrane Database Syst Rev. 2016;4:CD009794.

275. Shrewsbury VA, Baur LA, Nguyen B, Steinbeck KS. Transition to adult care in adolescent obesity: a systematic review and why it is a neglected topic. Int J Obes. 2014:38:475-9.

276. Bambra CL, Hillier FC, Moore HJ, Cairns-Nagi JM, Summerbell CD. Tackling inequalities in obesity: a protocol for a systematic review of the effectiveness of public health interventions at reducing socioeconomic inequalities in obesity among adults. Syst Rev. 2013;2:27.

277. Novak NL, Brownell KD. Role of policy and government in the obesity epidemic. Circulation. 2012;126:2345-52.

278. Farpour-Lambert NJ, Baker JL, Hassapidou M, et al. Childhood obesity is a chronic disease demanding specific health care - a position statement from the childhood obesity task force (COTF) of the European Association for the Study of obesity (EASO). Obes Facts. 2015;8:342-9.

279. The Regional Office for Europe of the World Health Organization. The challenge of obesity in the WHO European Region and the strategies for response. Summary. Branca F, Nikogosian H, Lobstein T, editors. World Health Organization; 2007.

280. Kamath CC, Vickers KS, Ehrlich A, et al. Behavioral interventions to prevent childhood obesity: a systematic review and meta-analyses of randomized trials. J Clin Endocrinol Metab. 2008;93:4606-15.

281. Waters E, de Silva-Sanigorski A, Hall BJ, et al. Interventions for preventing obesity in children. Cochrane Database Syst Rev. 2011;12:CD001871.

282. Gerards SM, Sleddens EF, Dagnelie PC, de Vries NK, Kremers SP. Interventions addressing general parenting to prevent or treat childhood obesity. Int J Pediatr Obes. 2011;6:e28-45.

283. Showell NN, Fawole O, Segal J, Wilson RF, et al. A systematic review of homebased childhood obesity prevention studies. Pediatrics. 2013;132:e193-200.

284. Golden H, Schneider M, Wood CAAP. Committee on nutrition. Preventing obesity and eating disorders in adolescents. Pediatrics. 2016;138:e20161649.

285. Oken E, Gillman MW. Fetal origins of obesity. Obes Res. 2003;11:496-506.

286. Ludwig DS, Rouse HL, Currie J. Pregnancy weight gain and childhood body weight: a within-family comparison. PLoS Med. 2013;10:e1001521.

287. Kaar JL, Crume T, Brinton JT, Bischoff KJ, McDuffie R, Dabelea D. Maternal obesity, gestational weight gain, and offspring adiposity: the exploring perinatal outcomes among children study. J Pediatr. 2014;165:509-15.

288. Mamun AA, Mannan M, Doi SA. Gestational weight gain in relation to offspring obesity over the life course: a systematic review and bias-adjusted meta-analysis. Obes Rev. 2014;15:338-47.

289. Williams CB, Mackenzie KS, Gahagan S. The effect of maternal obesity on the offspring. Clin Obstet Gynecol. 2014;57:508-15.

290. Starling AP, Brinton JT, Glueck DH, et al. Associations of maternal BMI and gestational weight gain with neonatal adiposity in the healthy start study. Am J Clin Nutr. 2015;101:302-9.

291. Hillier TA, Pedula KL, Vesco KK, Oshiro CE, Ogasawara KK. Impact of maternal glucose and gestational weight gain on child obesity over the first decade of life in normal birth weight infants. Matern Child Health J. 2016;20:1559-68.

292. Institute of Medicine. Weight gain during pregnancy: reexamining the guidelines. Washington: National Academies Press; 2009

293. Mund M, Louwen F, Klingelhoefer D, Gerber A. Smoking and pregnancy--a review on the first major environmental risk factor of the unborn. Int J Environ Res Public Health. 2013;10:6485-99.

294. Møller SE, Ajslev TA, Andersen CS, Dalgård C, Sørensen TI. Risk of childhood overweight after exposure to tobacco smoking in prenatal and early postnatal life. PLoS One. 2014;9:e109184.

295. Baidal WJA, Locks LM, Cheng ER, Blake-Lamb TL, Perkins ME, Taveras EM. Risk factors for childhood obesity in the first 1,000 days: a systematic review. Am J Prev Med. 2016;50:761-79. 
296. Gale C, Logan KM, Santhakumaran S, Parkinson JRC, Hyde MJ, Modi N. Effect of breastfeeding compared with formula feeding on infant body composition: a systematic review and meta-analysis. Am J Clin Nutr. 2012; 95:656-69.

297. Yan J, Liu L, Zhu Y, Huang G, Wang PP. The association between breastfeeding and childhood obesity: a meta-analysis. BMC Public Health. 2014;14:1267.

298. Horta BL, de Mola CL, Victora CG. Long-term consequences of breastfeeding on cholesterol, obesity, systolic blood pressure, and type-2 diabetes: systematic review and meta-analysis. Acta Paediatr Suppl. 2015;104:30-7.

299. Victora CG, Bahl R, Barros AJD, et al. Breastfeeding in the 21st century: epidemiology, mechanisms, and lifelong effect. Lancet. 2016;387:475-90

300. Seach KA, Dharmage SC, Lowe AJ, Dixon JB. Delayed introduction of solid feeding reduces child overweight and obesity at 10 years. Int J Obes. 2010; 34:1475-9.

301. Huh SY, Rifas-Shiman SL, Taveras EM, et al. Timing of solid food introduction and risk of obesity in preschool-aged children. Pediatrics. 2011;127:e544-51.

302. Weng ST, Redsell SA, Swift JA, Yang M, Glazebrook CP. Systematic review and meta-analyses of risk factors for childhood overweight identifiable during infancy. Arch Dis Child. 2012;97:1019-26.

303. Pearce J, Taylor MA, Langley-Evans SC. Timing of the introduction of complementary feeding and risk of childhood obesity: a systematic review. Int J Obesity (Lond). 2013;37:1295-306.

304. Vail B, Prentice $P$, Dunger DB, Hughes IA, Acerini CL, Ong KK. Age at weaning and infant growth: primary analysis and systematic review. J Pediatr. 2015;167:317-24.

305. Fewtrell M, Bronsky J, Campoy C, et al. Complementary feeding: a position paper by the European Society for Paediatric Gastroenterology, hepatology, and nutrition (ESPGHAN) committee on nutrition. J Pediatr Gastroenterol Nutr. 2017;64:119-32.

306. Pearce J, Langley-Evans SC. The types of food introduced during complementary feeding and risk of childhood obesity: a systematic review. Int J Obes. 2013;37:477-85.

307. Patro-Golab B, Zalewski BM, Kouwenhoven SMP, et al. Protein concentration in milk formula, growth, and later risk of obesity: a systematic review. J Nutr. 2016;146:551-64.

308. Foterek K, Hilbig A, Kersting M, et al. Age and time trends in the diet of young children: results of the Donald study. Eur J Nutr. 2016;55:611-20.

309. Voortman T, Braun KV, Kiefte-de Jong JC, et al. Protein intake in early childhood and body composition at age of 6 years: the generation R study. Int J Obes (London). 2016;40:1018-25.

310. Niinikoski $H$, Lagström $H$, Jokinen $E$, et al. Impact of repeated dietary counseling between infancy and 14 years of age on dietary intakes and serum lipids and lipoproteins the STRIP study. Circulation. 2007;116:1032-40.

311. Pan L, Li R, Park S, Galuska DA, Sherry BL, Freedman DS. A longitudinal analysis of sugar-sweetened beverage intake in infancy and obesity at 6 years. Pediatrics. 2014;134(Suppl 1):S29-35.

312. Cameron SL, Heath LM, Taylor RW. How feasible is baby led weaning as an approach to infant feeding? A review of the evidence. Nutrients. 2012;2: 1575-609.

313. Daniels L, Heath AL, Williams SM, et al. Baby-led introduction to SolidS (BLISS) study: a randomised controlled trial of a baby-led approach to complementary feeding. BMC Pediatr. 2015;15:179.

314. Brown A, Lee MD. Early influences on child satiety-responsiveness: the role of weaning style. Pediatr Obes. 2015;10:57-66.

315. World Health Organization. Global strategy on diet, physical activity and health. What can be done to fight the childhood obesity epidemic? In: Consideration of the evidence on childhood obesity for the commission on ending childhood obesity: report of ad hoc working group on science and evidence for ending childhood obesity. Geneva: WHO; 2016. http://www. who.int/elena/en.

316. Casas R, Sacanella E, Urpí-Sardà M, et al. Long-term immunomodulatory effects of a Mediterranean diet in adults at high risk of cardiovascular disease in the PREvención con Dleta MEDiterránea (PREDIMED) randomized controlled trial. J Nutr. 2016;146:1684-93.

317. D'Alessandro A, De Pergola G. Mediterranean diet pyramid: a proposal for Italian people. Nutrients. 2014;6:4302-16.

318. French SA, Story M, Neumark-Sztainer FJA, Hannan P. Fast food restaurant use among adolescents: associations with nutrient intake, food choices and behavioral and psychological variables. Int J Ob Relat Metab Disord. 2001;25: 1823-33.
319. Cobb LK, Appel LJ, Franco M, Jones-Smith JC, Nur A, Anderson CA. The relationship of the local food environment with obesity: a systematic review of methods, study quality, and results. Obesity (Silver Spring). 2015;23:1331-44.

320. Hu FB. Resolved: there is sufficient scientific evidence that decreasing sugarsweetened beverage consumption will reduce the prevalence of obesity and obesity-related diseases. Obes Rev. 2013;14:606-19.

321. Bucher Della Torre S, Keller A, Laure Depeyre J, Kruseman M. Sugarsweetened beverages and obesity risk in children and adolescents: a systematic analysis on how methodological quality may influence conclusions. J Acad Nutr Diet. 2016;116:638-59.

322. Malik VS, Pan A, C Willett W, Hu FB. Sugar-sweetened beverages and weight gain in children and adults: a systematic review and meta-analysis. Am J Clin Nutr. 2013;98:1084-102.

323. te Velde SJ, van Nassau F, Uijtdewilligen L, et al. Energy balance-related behaviours associated with overweight and obesity in preschool children: a systematic review of prospective studies. Obes Rev. 2012;13(Suppl 1):56-74.

324. Pate RR, O'Neill JR, Liese AD, et al. Factors associated with development of excessive fatness in children and adolescents: a review of prospective studies. Obes Rev. 2013;14:645-58.

325. Parikh T, Stratton G. Influence of intensity of physical activity on adiposity and cardiorespiratory fitness in 5-18 year olds. Sports Med. 2011;41:477-88.

326. Ortega FB, Ruiz JR, Castillo MJ, Sjöström M. Physical fitness in childhood and adolescence: a powerful marker of health. Int J Obes. 2008;32:1-11.

327. De Bock F, Genser B, Raat H, et al. A participatory physical activity intervention in preschools. Am J Prev Med. 2013;45:64-74.

328. Thompson DA, Christakis DA. The association between television viewing and irregular sleep schedules among children less than 3 years of age. Pediatrics. 2005;116:851-6.

329. Council on Communications and Media, Brown A. Media use by children younger than 2 years. Pediatrics. 2011;128:1040-5.

330. Tremblay MS, LeBlanc AG, Kho ME, et al. Systematic review of sedentary behaviour and health indicators in school-aged children and youth. Int J Behav Nutr Phys Act 2015. 2011;8:98.

331. Fröberg A, Raustorp A. Objectively measured sedentary behaviour and cardio-metabolic risk in youth: a review of evidence. Eur J Pediatr. 2014;173: 845-60.

332. Zhang G, Wu L, Zhou L, Lu W, Mao C. Television watching and risk of childhood obesity: a meta-analysis. Eur J Pub Health. 2016;26:13-8.

333. Schmidt ME, Haines J, O'Brien A, et al. Systematic review of effective strategies for reducing screen time among young children. Obesity (Silver Spring). 2012;20:1338-54.

334. Cauchi D, Glonti K, Petticrew M, Knai C. Environmental components of childhood obesity prevention interventions: an overview of systematic reviews. Obes Rev. 2016;17:1116-30.

335. Benatti FB, Ried-Larsen M. The effects of breaking up prolonged sitting time: a review of experimental studies. Med Sci Sports Exerc. 2015;47:2053-61.

336. Fisher A, Mc Donald LM, van CHN J, et al. Sleep and energy intake in early childhood. Int J Obes (Lond). 2014;38:926-9.

337. Koren D, Dumin M, Gozal D. Role of sleep quality in the metabolic syndrome. Diabetes Metab Syndr Obes. 2016:9:281-310.

338. Fatima Y, Doi SA, Mamun AA. Longitudinal impact of sleep on overweight and obesity in children and adolescents: a systematic review and biasadjusted meta-analysis. Obes Rev. 2015;16:137-49.

339. Yoong SL, Chai LK, Williams CM, Wiggers J, Finch M, Wolfenden L. Systematic review and meta-analysis of interventions targeting sleep and their impact on child body mass index, diet, and physical activity. Obesity (Silver Spring). 2016;24:1140-7.

340. Paruthi S, Brooks LJ, D'Ambrosio C, et al. Recommended amount of sleep for pediatric populations: a consensus statement of the American Academy of sleep medicine. J Clin Sleep Med. 2016;12:785-6.

341. Effective Health Care Program. Childhood obesity prevention programs: comparative effectiveness review and meta-analysis. Comparative effectiveness review number 115. Rockville: AHRQ Publication No. 13EHC081-EF; 2013.

342. Wang $Y$, Cai $L$, Wu $Y$, et al. What childhood obesity prevention programs work. A systematic review and meta-analysis. Obes Rev. 2015;16:547-65. 